\title{
COMPORTAMENTO INTRAVERBAL: AQUISIÇÃO, REVERSIBILIDADE E CONTROLE MÚTIPLO DE VARIÁVEIS
}

\author{
INTRAVERBAL BEHAVIOR: ACQUISITION, REVERSIBILITY, AND MULTIPLE \\ CONTROL
}

\author{
Maxleila Reis M. Santos e Maria Amalia Pie Abib Andery \\ PONTIFÍCIA UNIVERSIDADE CATÓLICA DE SÃO PAULO, BRASIL
}

\begin{abstract}
RESUMO
Comportamento intraverbal foi definido como um operante verbal no qual a resposta está sob controle de estímulo discriminativo verbal sem correspondência ponto a ponto entre estímulo e resposta. Traduções entre línguas podem ser casos de comportamento intraverbal. No presente experimento investigou-se (a) a produção de comportamento intraverbal entre pares de palavras português-inglês e inglês-português, (b) se a aquisição de comportamento novo sofreria efeito de treino anterior, (c) se o estabelecimento de comportamento intraverbal seria suficiente para a emissão de comportamento intraverbal simétrico (reversibilidade) e (d) como variáveis relacionadas a outros operantes verbais interfeririam na aquisição. Participaram do estudo 11 jovens com pouco conhecimento de inglês. Foi empregado um procedimento de treino intraverbal no qual uma palavra-estímulo (em português ou inglês) era apresentada em uma tela do computador e o participante digitava a palavra correspondente em outra língua (inglês ou português). Foram treinados 30 pares de palavras, 15 em inglês-português e 15 em portuguêsinglês. Em fases de reversão foram testadas e treinadas as mesmas palavras na direção simétrica: palavras estímulo foram apresentadas na língua anteriormente exigida como resposta. Para controlar efeitos de ordem, os participantes foram distribuídos em 2 grupos, nos quais as direçôes de treino foram invertidas. Todos os participantes adquiriram rapidamente comportamento intraverbal preciso, embora o treino inglês-português tenha sido mais fácil em todos os casos. Nas reversóes houve poucos casos de simetria (reversibilidade), embora o treino tenha sido mais curto, indicando efeitos de treino anterior. Uma análise de erros durante a aquisição sugeriu que variáveis que caracterizam comportamento textual e de transcrição, além de efeitos de generalização relacionados ao conjunto de palavras treinadas, participaram do controle do comportamento intraverbal.
\end{abstract}

Palavras-chave: intraverbal, comportamento verbal, operantes verbais, textual, transcrição.

\begin{abstract}
Intraverbal behavior is a verbal operant in which a verbal stimulus is the occasion for a particular verbal response to be emitted, but there is no point-to-point correspondence between stimulus and response. Translation is a special case of intraverbal behavior. The aim of the present study was to investigate (a) the production of intraverbal behavior of word pairs in English-Portuguese and Portuguese-English, (b) if the acquisition of intraverbal behavior would influence further acquisition of new intraverbal behavior, (c) if training intraverbal behavior would lead to the emergence of new symmetrical intraverbal behavior, and (d) if and how variables related to other verbal operants influenced acquisition of intraverbal behavior. Eleven young adults, whose native language was Portuguese, with little knowledge of English, participated in the study. During training a stimulus-word (in English or Portuguese) was presented on a computer screen and the participant typed the correspondent word in the other language (Portuguese or English): 30 intraverbal responses were trained, half on English-Portuguese and the other half on Portuguese-English. Two training conditions were followed by two reversal conditions, during which stimuli - words - were presented in the language previously required as response. Order effects were controlled balancing the direction of training (English-Portuguese or Portuguese-English) of the words between two groups of participants. Results showed that: (a) all participants acquired precise intraverbal behavior, although the training direction English-Portuguese was faster; (b) training had an effect on subsequent training and on symmetrical training, (c) there were few cases of immediate emergence of symmetrical intraverbal behavior; and (d) an error analysis showed that besides generalization effects, textual and transcription behaviors interfered during acquisition.

Key words: intraverbal, verbal behavior, verbal operants, textual, transcription

Este trabalho é produto da dissertação de mestrado da primeira autora (Treino de relaçôes intraverbais e implicaçôes para a reversibilidade da relação), conduzida sob orientação da segunda autora no Programa de Psicologia Experimental: Análise do Comportamento da PUC-SP. A primeira autora teve apoio CAPES, na forma de bolsa de mestrado, e a segunda autora teve apoio do CNPq, na forma de bolsa Produtividade em Pesquisa. Correspondência por email:mandery@pucsp.br.
\end{abstract}


No livro Verbal behavior (1957), Skinner delineou um programa de pesquisas para a área, para o qual propôs como um dos primeiros passos a análise das contingências envolvidas no comportamento do falante (Andery \& Sério, 2003; Michael, 1984; Richelle, 1976).

Comportamento verbal foi então definido como comportamento operante que se caracteriza por estabelecer uma relação mediada com o ambiente. Deve receber especial atenção por ser comportamento operante que não altera o ambiente via relaçôes que podem ser mecanicamente descritas, uma vez que as conseqüências que mantêm o comportamento dependem da ação de outra pessoa - o ouvinte - especialmente treinada pela comunidade verbal para assim proceder (Skinner, 1957, 1974).

Além da audiência ocasional relevante, comportamento verbal não requer suporte ambiental. Precisa-se de uma bicicleta para andar de bicicleta, mas não para dizer "bicicleta”. Por isso, o comportamento verbal pode ocorrer em quase todas ocasiōes (Skinner, 1974, p. 89).

Está implícito na definição de comportamento verbal que as contingências de três termos que descrevem o comportamento do falante necessariamente envolvem uma outra contingência, que descreve o comportamento do ouvinte, que participa como ambiente comportamentalmente relevante do comportamento do falante.

Ao analisar as contingências de reforçamento características do comportamento verbal, Skinner (1957) propôs uma classificação que descreveria os comportamentos do falante - os operantes verbais - categorizando- os em seis tipos: mando, tato, ecóico, textual, transcrição e intraverbal. Ainda que em ritmo menor do que o desejável, como sugeriram Andery (2001), Michael (1984, 1998), Normand, Fossa, \& Poling (2000), Oah e Dickinson (1989), Sautter e LeBlanc (2006), e Sundberg (1998), desde então acumularamse estudos empíricos e experimentais de analistas do comportamento sobre comportamento verbal com foco nos diferentes operantes verbais (por exemplo, Arntzen \& Almas, 2002; Baer \& Detrich, 1990; Bourret, Vollmer \& Rapp, 2004; Hall \& Sundberg, 1987; Hubner, 2003 ; Lamarre \& Holland, 1985; Lee \& Sanderson, 1987; Murphy, BarnesHolmes \& Barnes-Holmes, 2005; Partington \& Bailey, 1993; Petursdottir, Carr \& Michael, 2005; Polson, Grabavac \& Parsons, 1997; Ribeiro, 1989; Stafford, Sundberg, \& Braam, 1988; Tenenbaum \& Wolking, 1989; Wallace, Iwata \& Hanley, 2006; Yi, Christian, Vittinberga, \& Lowenkron, 2006) ${ }^{1}$.

Em sua classificação Skinner (1957) destacou, entre os operantes verbais sob controle de estimulação antecedente, aqueles nos quais os estímulos antecedentes que controlam a emissão de respostas verbais específicas são estímulos verbais: os operantes verbais ecóico, textual, transcrição e intraverbal. Quando tratou dos operantes verbais em que as respostas do falante são controladas por estímulos verbais, Skinner fez ainda outra distinção: operantes que guardavam relaçôes de 'correspondência ponto-a-ponto' entre estímulo verbal antecedente e resposta verbal - ecóico, textual e transcrição - e operantes nos quais as relações entre estímulo antecedente verbal e resposta não seriam de correspondência ponto a

\footnotetext{
1 Nos últimos anos vem aumentando o número de dissertações e teses sobre diferentes operantes verbais, em contextos aplicados e de pesquisa básica, no Brasil. No entanto, uma rápida revisão das revistas brasileiras nas quais usualmente são publicados relatos de pesquisa da área revelou que esses trabalhos não estão ainda publicados.
} 
ponto - comportamento intraverbal. Chamouse de correspondência ponto-a-ponto relações nas quais partes específicas (e delimitáveis) do estímulo verbal controlariam a forma (a topografia) de partes específicas (e identificáveis) da resposta verbal.

No presente trabalho o foco de interesse foi o operante verbal que é controlado por estímulo antecedente verbal, mas no qual a resposta verbal não tem topografia que guarda correspondência ponto-a-ponto com o estímulo que a evoca, o chamado comportamento intraverbal:

No comportamento ecóico e no ato de escrever a partir de uma cópia existe uma correspondência formal entre o estímulo e a resposta produzida. No comportamento textual e na tomada de um ditado existe uma correspondência ponto a ponto entre sistemas dimensionais diferentes. Mas algumas respostas verbais não apresentam correspondência ponto a ponto com os estímulos verbais que as evocam. É o caso de respondermos 'quatro' ao estímulo verbal 'dois mais dois', ou 'à bandeira' para 'eu juro fidelidade', ou 'Paris' para 'a capital da França', ou '1066' para 'Guilherme, o Conquistador'. Podemos chamar o comportamento controlado por tais estímulos de intraverbal. Uma vez que correspondências formais não estão em jogo, podemos considerar os estímulos vocais e escritos e as respostas vocais e escritas nas quatro combinações ao mesmo tempo (Skinner, 1957, p.71).

Como foi destacado, o operante verbal intraverbal é controlado, ou melhor, evocado, por estímulo discriminativo verbal, que pode ser tanto vocal quanto escrito. A reposta verbal pode ser vocal ou escrita, mas sua topografia não guarda uma correspondência formal com o estímulo discriminativo que a evoca. As conseqüências que mantêm essa resposta são reforçadores generalizados, como no caso de todos os outros operantes verbais sob controle de estímulos antecedentes discriminativos. Relações intraverbais são comuns e estão presentes nas interaçôes sociais cotidianas, como, por exemplo: “Como vai você??" E a resposta verbal "Bem, obrigado". O comportamento intraverbal também desempenha papel importante em muitas outras interações sociais (conversas, canções, descrição de uma história) e é, pelo menos em parte, o produto de processos de ensino, que reconhecemos como habilidades acadêmicas.

Quando um longo poema é recitado, freqüentemente podemos explicar a maior parte do recitar supondo apenas que uma parte controla a outra de maneira intraverbal. Se interrompermos o falante, o controle pode se perder; mas voltar ao início o restabelece, uma vez que recria o estímulo verbal adequado. $\mathrm{O}$ alfabeto é adquirido como uma série de respostas intraverbais, assim como contar, adicionar, multiplicar e reproduzir tabelas matemáticas em geral. A maior parte dos "fatos" da história são adquiridos e retidos como respostas intraverbais. O mesmo ocorre com fatos da ciência, embora nesse caso também haja freqüentemente respostas sob outro tipo de controle... [tato] Uma pergunta constitui muitas vezes o estímulo para uma longa resposta sem que haja outra variável controladora importante. Os espaços para completar itens em uma prova objetiva estimulam respostas intraverbais mais ou menos do mesmo modo. Muitas aparentes metáforas e alusōes literárias têm freqüentemente origem apenas intraverbal (Skinner, 1957, p. 72).

Em um artigo no qual apresentam resultados de uma pesquisa sobre desenvolvimento 
de comportamento intraverbal, Partington e Bailey (1993), ecoando Skinner, ressaltaram que dada a extensão do comportamento intraverbal nos falantes, o desenvolvimento de repertórios intraverbais tem considerável importância. Afirmaram também que, apesar de considerarem heurística a proposta de análise do comportamento verbal de Skinner, analistas do comportamento fizeram poucos estudos sobre "linguagem" (repertório verbal) em crianças com desenvolvimento típico - e menos ainda sobre o desenvolvimento de comportamento intraverbal. A literatura da área lista muito mais estudos que pretendem desenvolver tecnologias de ensino de comportamento verbal para indivíduos com desenvolvimento atípico, e especialmente os comportamentos de mando e tato. $\mathrm{Na}$ tentativa de identificar as fontes de controle sobre o comportamento dos pesquisadores, Partington e Bailey (1993) apontaram a rápida e freqüente aquisição de múltiplos operantes verbais em crianças com desenvolvimento típico como características que dificultariam a distinção entre os operantes verbais e o seu estudo. Estas peculiaridades possivelmente tornaram difícil o desenvolvimento de procedimentos e medidas que seriam necessários em estudos sobre operantes verbais específicos dos quais participassem indivíduos com repertórios verbais considerados típicos.

Pode-se supor que no caso do comportamento intraverbal essas dificuldades sejam especialmente importantes, uma vez que a ausência de correspondência ponto a ponto entre estímulo e resposta verbal, de um lado, e a ausência de estimulação não verbal antecedente específica (estímulo não verbal ou operação estabelecedora), de outro, tornariam mais difícil ainda o estudo de comportamento intraverbal em situações controladas.
Sugestiva do problema apontado é a revisão de pesquisas empíricas influenciadas pelo livro Verbal behavior (1957) feita por Oah e Dickinson (1989), que selecionaram artigos publicados com base em dois critérios: haver referência ao livro Verbal behavior e o estudo citar pelo menos um dos operantes verbais (incluindo o autoclítico). Nessa revisão apenas três estudos tinham em seus títulos a palavra "intraverbal": Braam e Poling (1983); Chase, Johnson e Sulzer-Azaroff (1985), e Luciano (1986), mas podemos citar outros estudos empíricos sobre comportamento intraverbal, subdivididos em três conjuntos.

O primeiro conjunto envolveu estudos que desenvolveram e testaram procedimentos para instalar repertório intraverbal específico, com respostas unitárias, em indivíduos com desenvolvimento atípico (Braam \& Poling, 1983; Luciano, 1986; Watkins, Pack Teixeira \& Howard, 1989), ou com lesão cerebral adquirida (Sundberg, San Juan, Dawdy \& Argüelles, 1990) e estudos que testaram procedimentos para desenvolver repertório intraverbal em crianças com desenvolvimento típico (Partington \& Bailey, 1993). Esses estudos investigaram o desenvolvimento e estabelecimento de operantes intraverbais, em geral utilizando o que os autores chamaram de procedimentos de transferência de controle de estímulos.

Braam e Poling (1983) ensinaram repertório intraverbal a crianças diagnosticadas com retardo mental apresentando aos participantes estímulos não-verbais, tais como figuras de objetos, quando eles não emitiam uma reposta intraverbal a um estímulo verbal (sinal manual): o experimentador sinalizava uma classe de substantivos - por exemplo, 'alimento' - e a reposta intraverbal considerada correta consistia na sinalização de itens pertencentes à classe 
'alimentos', por exemplo: maçã, laranja, cachorro-quente. Quando o participante não emitia a resposta intraverbal correta, figuras dos itens que pertenciam à classe eram apresentadas. Em tentativas posteriores o procedimento era repetido até que respostas intraverbais fossem emitidas diante apenas do estímulo verbal.

Luciano (1986) replicou o trabalho de Braam e Poling (1983) com indivíduos com desenvolvimento atípico. Seus participantes também aprenderam a emitir respostas verbais sob controle de estímulos verbais (comportamento intraverbal) a partir de um procedimento de treino no qual estímulos verbais foram sistematicamente pareados com estímulos não verbais que evocavam respostas verbais.

Watkins e cols. (1989) também trabalharam com crianças com desenvolvimento atípico. Em seu procedimento de treino de respostas intraverbais simples e múltiplas transferiram o controle de uma dica ecóica para um estímulo verbal. As perguntas envolviam solicitação ao participante para que nomeasse substantivos animais, brinquedos, roupas, ou mobiliário - ou adjetivos - texturas, cores, tamanhos. Nos treinos de respostas múltiplas, depois que o participante respondia uma pergunta (por exemplo: 'qual é uma cor?' - o experimentador pedia: "mais uma...' e assim sucessivamente. No treino, as respostas esperadas eram emitidas pelo experimentador e repetidas pelo participante. Os resultados mostraram que o treino foi eficiente. Testes posteriores para testar se as topografias de repostas estabelecidas como comportamento intraverbal seriam emitidas como tato indicaram que o treino direto parece ser necessário.

Sundberg e cols. (1990), trabalhando com pacientes que sofreram lesão cerebral em acidentes e perderam parte de seu repertório verbal, também treinaram comportamento verbal que envolvia certas topografias de respostas, provocando a emissão dessas respostas incialmente sob controle de outras variáveis.

Partington e Bailey (1993) trabalharam com crianças com desenvolvimento típico. Utilizando um delineamento de linha de base múltipla treinaram respostas intraverbais às perguntas 'quais são algumas frutas?', 'quais são algumas coisas de limpeza?', 'quais são alguns brinquedos?' Depois de um treino de tatos em que figuras em cartões - de frutas, produtos de limpeza, brinquedos e mobílias - passaram a evocar consistentemente respostas específicas, iniciou-se o treino intraverbal: junto com a pergunta eram apresentados cartóes com figuras que evocavam respostas verbais de mesma topografia que as respostas intraverbais a serem instaladas. A apresentação das figuras foi então sistematicamente atrasada. Os resultados mostraram que o treino instalava cadeias verbais nas quais as perguntas controlavam respostas verbais com vários elementos. Os resultados indicaram também que o treino de tatos foi eficiente como etapa no treino subseqüente do comportamento intraverbal, mas não foi suficiente para evocar as respostas verbais de mesma topografia que as respostas de tato, em situações características de comportamento intraverbal.

Em todos esses estudos, os procedimentos empregados instalaram ou fortaleceram operantes específicos, mais comumente tatos (respostas verbais sob controle de estímulos discriminativos não-verbais) e, em seguida, proveram reforçamento para respostas de mesma topografia emitidas também na presença de estímulos verbais (e, não só, dos estímulos não verbais controladores da resposta de tato já instalada). Esta etapa em geral foi seguida de algum procedimento para retirada gradual dos estímulos não-verbais - fading - controladores 
da resposta verbal. Os procedimentos que resultam em transferência de controle de estímulos, envolveram o estabelecimento de novas, ou mais complexas, formas de controle de estímulos sobre o responder: partindo do controle já estabelecido sobre o repertório verbal do sujeito e gradualmente transferindo o controle para dimensões de estímulo que não exerciam controle sobre o responder. Nestes casos, relatam-se em geral resultados positivos, porém há que se ressaltar que tais estudos ocorrem em situações bem controladas e os resultados são relativos ao estabelecimento de pequeno número de operantes.

Um segundo subconjunto de estudos foi encontrado na revisão de literatura de estudos empíricos. Tais estudos têm características bem distintas daqueles até aqui referidos, nos quais respostas verbais muito específicas são evocadas por estímulos verbais também específicos (e típicos de tatos) em tentativas discretas. Neste segundo conjunto de estudos classificados como relacionados com comportamento intraverbal, os autores ocuparam-se de produzir comportamento intraverbal considerado mais complexo, no sentido de envolver respostas verbais compostas de mais de uma palavra e que envolvem o que comumente se chama de sentenças gramaticais.

Nesta direção, os experimentos conduzidos por Bennett e Ling (1972) e por Wheeler e Sulzer (1970) poderiam ser classificados como de comportamento intraverbal, embora o termo não seja empregado pelos autores: mais uma vez trabalhando com indivíduos com desenvolvimento atípico, em ambos os estudos foram treinadas "respostas verbais complexas": respostas gramaticalmente corretas compostas de sujeito e predicado, envolvendo sempre um pronome, substantivo, verbo, substantivo/adjetivo ('o menino está comendo maçã'). Os participantes podiam nomear figuras (tatos) e imi- tar respostas verbais do experimentador (ecóico). Durante o treino, o experimentador apresentava cartôes com figuras e emitia a resposta verbal a ser ecoada. Os treinos nos dois estudos envolveram especificamente a forma gramatical: 'pronome - substantivo - verbo - substantivo/ adjetivo'. No decorrer do treino uma sucessão de cartôes passou a controlar cadeias verbais, tais como: 'o menino está comendo maçã'. Os treinos encerravam-se quando frases inteiras podiam ser emitidas com apenas um estímulo inicial (um cartão). O comportamento verbal resultante desses treinos ficou fortemente sob controle de estímulos antecedentes verbais e por esta razão os estudos foram aqui tomados como estudos sobre aquisição de comportamento intraverbal.

O estudo publicado por Garcia (1974) também poderia ser tomado como trabalho no qual se instalou comportamento intraverbal "complexo". Treinou-se e posteriormente testou-se generalização de cadeias intraverbais, envolvendo conversação entre dois falantes: o experimentador e o participante, que era sempre um indivíduo com desenvolvimento atípico. Embora as cadeias intraverbais se encerrassem sempre com a obtenção de um item específico - o que é sugestivo de um forte controle por reforçadores específicos, típicos de mandos ainda assim, os participantes do estudo de Garcia passaram a emitir respostas verbais sob controle de outras respostas verbais sem relação ponto a ponto entre estímulo e resposta.

Finalmente, foram localizadas na revisão de literatura pesquisas que investigaram o estabelecimento e desenvolvimento de relações intraverbais envolvidas em repertórios acadêmicos específicos - tais como, formação de conceitos, leitura compreensiva e tradução - e que discutiram questôes específicas a cada uma das 
relaçôes estudadas Destacam-se neste caso os relatos de Chase e cols. (1985); Tenenbaum e Wolking (1989) e Polson e cols. (1997).

Chase e cols. (1985) trabalharam com alunos universitários. Conceitos foram ensinados por meio de três tipos de relações intraverbais: definição, exemplificação e perguntas de identificação. Em testes posteriores, foram feitas perguntas semelhantes ao treino e tipos de perguntas não utilizados nos treinos. Os resultados indicaram mais erros quando as perguntas utilizadas eram de tipos diferentes daqueles treinados. Os autores sugeriram em suas conclusões que o comportamento intraverbal poderia ser subdividido em subcategorias a depender do tipo de estímulo verbal empregado e do tipo de resposta verbal exigidas.

Já Tenenbaum e Wolking (1989) testaram os efeitos de inflexão e rapidez de leitura (comportamento textual) sobre respostas que avaliavam a compreensão da leitura, que consideraram como sendo respostas intraverbais e concluíram que leitura rápida e com inflexão semelhante à da "linguagem oral" produzia respostas intraverbais mais precisas.

De especial interesse aqui foi o trabalho de Polson e cols. (1997), que investigaram o estabelecimento de comportamento intraverbal e o teste de sua reversibilidade. $\mathrm{O}$ estudo envolveu a tradução: palavras apresentadas em uma língua (inglês ou francês) deveriam, com o treino, evocar respostas verbais que eram palavras escritas na outra língua (francês ou inglês, respectivamente). As relações estímulo verbal-resposta verbal treinadas foram consideradas relações intraverbais, de acordo com a classificação de Skinner (1957), pois diante de um estímulo verbal (palavra em inglês ou francês) exigiase uma resposta verbal (palavra em francês ou inglês) que não guardava correspondência ponto a ponto com o estímulo discriminativo. Os autores estavam interessados em investigar se o que chamaram familiaridade com os estímulos e respostas interferiria no treino dessas relaçôes intraverbais e se uma vez estabelecido um desempenho preciso e fluente, ocorreria a reversão de pares de estímulos-respostas. Considerando que fluência seria um objetivo desejável na educação, Polson e cols. (1997) discutiram seus resultados em termos de fluência - definida como uma combinação de precisão e velocidade que caracteriza desempenho competente, e medida como freqüência de respostas precisas por unidade de tempo.

Participaram do estudo nove estudantes universitários americanos falantes de inglês. Os participantes passavam por um pré-teste de conhecimento de francês na forma escrita. Os critérios para seleção dos participantes foram (a) que eles digitassem com velocidade de no mínimo 30 palavras por minuto, (b) com pouco ou nenhum erro.

Para a realização da pesquisa foi utilizado um programa de computador para ensinar 16 pares de palavras inglês-francês ou francês-inglês, sendo que cada palavra era composta por seis a oito letras.

Cada tentativa começava com a apresentação, no centro da tela do computador, de uma palavra-estímulo escolhida randomicamente pelo programa. Em uma caixa, localizada no terço inferior da tela, chamada de caixa de digitação da resposta, ficava disponível um cursor piscante que indicava o que seria o início da palavra, quando digitada. A tela também continha instruções do que o participante poderia fazer: digitar a palavra, pressionar a tecla TAB para obter uma dica, ou pressionar a tecla ENTER para pular a palavra apresentada. Diante de uma palavra-estímulo, a digitação 
de uma tecla correta no teclado, ou a pressão à tecla TAB, apresentava na caixa de digitação da resposta a letra correta e, então, o cursor se movimentava para posição seguinte. Uma letra digitada errada produzia um beep baixo e o cursor se mantinha no mesmo lugar.

Após cinco letras digitadas incorretamente, considerava-se encerrada a tentativa de uma palavra-estímulo (registrada como "resposta errada"). Uma resposta correta - palavra completada - era seguida pela mensagem "good!" e um beep. Uma resposta incorreta era conseqüenciada com a mensagem "Wrong, too many errors!" e com um beep baixo. A tecla ENTER, quando acionada, imediatamente revelava, por 0,33 segundos, toda a palavra, acompanhada da mensagem "Skip!"; em tal caso a resposta era considerada incorreta.

Encerrada a tentativa a tela era reiniciada e uma nova palavra era apresentada. Quando a última palavra do conjunto era completada, uma tela com a pontuação alcançada era apresentada, incluindo: a duração das tentativas, o número de palavras completadas (de 16), de palavras incorretas e percentual de acertos (precisão). Começava então um novo ciclo, no qual a lista de 16 palavras-estímulo era apresentada novamente em ordem randômica. As condiçôes experimentais encerravam-se quando um dado tempo de sessão havia decorrido.

Se a opção chamada palavra precisa estivesse acionada, uma resposta só era considerada correta se nenhuma letra fosse digitada incorretamente (Experimentos $1 \mathrm{e}$ 2). Se esta opção estivesse desligada (Experimento 3), uma resposta era considerada cor- reta se a primeira letra fosse digitada corretamente e se não houvesse mais que três erros até a palavra ser completada.

No Experimento 1 foram manipuladas as palavras-estímulo. No Experimento 2 manipulou-se também a duração de cada sessão em cada condição e a ordem dos cartôes foi randomizada entre os sujeitos. No Experimento 3 a opção palavra precisa foi desligada.

$\mathrm{Na}$ Condição 1 de cada um dos experimentos, oito palavras-estínulo eram apresentadas em francês e se exigia resposta digitada em inglês (Francês-Inglês) e as outras oito palavras envolviam a relação inversa: do inglês para o francês (Inglês-Francês). Na Condição 2 havia uma reversão, palavras antes apresentadas em inglês eram apresentadas em francês e vice-versa.

Assim, nos três experimentos Polson e cols. (1997) manipularam a direção do treino, mensurando o que ocorreu com: (1) a fluência, ou seja, a taxa de respostas corretas para cada palavra nas duas condições, e (2) a precisão das respostas diante de palavras em inglês ou francês.

Os resultados dos Experimentos 1 e 2, que diferiram na ordem de apresentação das palavras e no tempo de sessão, mostraram que o desempenho piorou drasticamente na reversão e que este efeito foi maior quando o par intraverbal revertido envolveu uma resposta não familiar, ou seja, quando o par envolveu palavra-estímulo em inglês e palavra-resposta em francês. Os resultados da primeira tentativa da Condição 2, semelhante a um teste de simetria, não mostraram a rápida emergência de simetria que é típica da literatura de equivalên-

\footnotetext{
2 Michael (1985) propôs uma distinção entre linguagem baseada em seleção e linguagem baseada em topografia. Chamou de linguagem baseada em seleção comportamento verbal no qual o falante responde selecionando (por exemplo, apontando) um estímulo (em geral visual) de um conjunto de estímulos. Neste caso, distintas respostas verbais dependem de diferentes estímulos selecionados, mas a topografia da resposta é sempre a mesma (por exemplo, apontar). Michael chamou de linguagem baseada em topografia o comportamento verbal no qual respostas verbais diferentes (orais, escritas, ou gestuais) envolvem diferentes topografias. As respostas verbais no primeiro caso envolvem contingências de discriminação condicional e no segundo caso contingências de discriminação simples.
} 
cia de estímulos (Sidman, 1994, 2000) e que, em geral, exige respostas envolvendo linguagem baseada em seleção ${ }^{2}$. Neste caso, em que as respostas verbais são topograficamente distintas, no entanto, para todos os participantes a aquisição na Condição 2 foi mais rápida que na Condição 1.

Os resultados do Experimento 3 (em que o critério de acerto foi mudado) replicaram os demais resultados: ao se reverter as palavras-estímulo e palavras-resposta as taxas de respostas corretas e a precisão foram dramaticamente reduzidas, exceto para um participante. No entanto, diferenças entre os treinos francês-inglês e inglês-francês não foram tão aparentes como nos experimentos anteriores. $\mathrm{O}$ critério de acerto mais condescendente parece ter facilitado a precisão para o par inglês-francês.

Várias questões dirigiram o presente trabalho, no qual pretendeu-se ampliar a análise iniciada no estudo de Polson e cols. (1997): (1) Será que o procedimento de treino intraverbal de grupos de palavras envolvendo reforçamento diferencial imediato, estímulos escritos e respostas escritas, empregado por Polson e cols., seria efetivo para a produção de pares de operantes intraverbais envolvendo palavras em PortuguêsInglês (PI) e Inglês-Português (IP)?

(2) Será que o treino de um grupo de pares de palavras teria efeito sobre treinos sucessivos de novos pares de palavras? (3) Será que o treino de operantes intraverbais que envolve pares de palavras em duas línguas promoveria a emissão de comportamento verbal simétrico ao comportamento treinado sem treino adicional com precisão? (4) $\mathrm{O}$ procedimento empregado seria igualmente efetivo em ambas as direções de treino (PI e IP)? Esta pergunta é importante, especialmente considerando-se que o procedimento envolve também comportamento textual, com os estímulos apresentados visualmente como palavras escritas em uma tela de computador - e comportamento de transcrição - as respostas dos participantes foram compostas como respostas escritas (digitadas); e (5) O procedimento permitiria explorar a multideterminação de operantes verbais simples? Uma análise de "erros" no treino permitiria identificar o controle de mútiplas variáveis sobre o processo de seleção do comportamento? Como o treino intraverbal empregado necessariamente envolve comportamento textual (a "leitura" de palavra), comportamento de transcrição (semelhante a cópia e até mesmo a ditado) e, possivelmente, outros comportamentos intraverbais já instalados para palavras conhecidas e que poderiam emergir durante o treino para as palavras novas tais controles poderiam ser identificados na análise dos resultados?

\section{MÉTODO}

\section{Participantes}

Participaram do presente estudo 11 adultos com idade entre 18 e 26 anos de ambos os sexos, sem história experimental anterior. Todos os participantes que aceitaram participar da pesquisa assinaram um termo de consentimento informado. O projeto foi submetido ao Comitê de Ética da Universidade e recebeu aprovação.

No recrutamento, os potenciais participantes eram informados de que estavam sendo selecionadas pessoas com algum conhecimento de inglês. Pedia-se aos participantes que avaliassem (oralmente) sua habilidade de traduzir palavras do inglês para o português e vice-versa e perguntava-se se o participante digitava em computador e se sentia capaz de digitar palavras em inglês diante de palavras em português. 
Um pré-teste avaliou o conhecimento de inglês para efeitos do estudo. No pré-teste o participante foi solicitado a traduzir (escrevendo) uma lista de 40 palavras escritas em inglês - 30 das quais fizeram parte do treino. Os candidatos que tiveram mais de cinco acertos no teste foram excluídos.

\section{Material e Equipamento}

As sessões experimentais ocorreram em uma sala silenciosa. O participante manipulava individualmente em um notebook e ao lado do computador ficava uma folha com as instruções impressas. Durante o estudo algumas teclas do notebook foram cobertas deixando livres para a digitação os caracteres relativos a letras e as teclas tab, enter e barra de espaço. O notebook foi equipado com um software especialmente desenvolvido para o presente estudo, na linguagem C\# Microsoft $t^{3}$. O programa controlava as contingências da sessão e registrava informaçôes sobre as tentativas e o desempenho dos participantes em cada tentativa: a palavra-estímulo apresentada na tentativa, os caracteres digitados (corretos e incorretos), as pressóes às teclas tab e enter em cada tentativa, o momento da digitação (contado do início da tentativa), a duração da tentativa (momento de início e final da tentativa) e o número de palavras corretas e incorretas por minuto.

O experimentador não permaneceu na sala de coleta durante a sessão.

\section{Procedimento}

Pressionar a barra de espaço iniciava uma tentativa. A cada tentativa uma palavra-estímulo era apresentada na parte superior da tela do computador. A palavra-estímulo era apresentada em letra tamanho 36 e a tarefa do partici- pante era digitar a palavra correspondente (palavra-resposta) em outra língua. Se a palavraestímulo fosse apresentada em português, o participante digitava a palavra correspondente em inglês (treino Português-Inglês, ou PI) e se a palavra estímulo estivesse em inglês, o participante digitava sua tradução em português (treino Inglês-Português, ou IP).

$\mathrm{Na}$ parte inferior da tela, abaixo da palavra-estímulo, era apresentada uma caixa com 11 traços que eram preenchidos seqüencialmente, cada vez que o participante digitava uma tecla, com a letra correspondente. Ou seja, cada letra digitada era apresentada no traço. No início da tentativa o cursor ficava no traço mais à esquerda e se movia a cada letra digitada. O cursor só se movia quando a letra era digitada. Se a letra digitada não fosse considerada correta o cursor não se movia.

As palavras utilizadas no treino. Foram selecionados 30 pares de palavras, dos quais 20 pares foram utilizados nas Fases 1 e 2 e os 10 restantes nas Fases 3 e 4 . Todas as palavras eram substantivos com pouca probabilidade de serem conhecidos de falantes do inglês como segunda língua, tais como nomes de ferramentas, animais e plantas pouco comuns, mobiliário e peças de automóveis (Tabela 1). As palavras na língua inglesa continham de 4 a 9 letras e as palavras em português eram compostas de 4 a 11 letras.

Para contrabalancear eventuais efeitos de ordem de treino, dividiu-se o bloco de 20 palavras das Fases 1 e 2 e o bloco de 10 palavras das Fases 3 e 4 em dois subconjuntos (de 10 ou 5 palavras): para um grupo de participantes um dos subconjuntos de palavras foi apresentado em uma língua nas Fases 1 e 3 e para outro grupo o outro subconjunto. Nas fases de

3 O programa foi desenvolvido por Luís Guilherme Pereira Lima atendendo às especificações do pesquisador. 
reversão (Fases 2 e 4) inverteu-se o treino. $\mathrm{Na}$ Tabela 1 estão listadas as palavras em suas respectivas direçôes de treino nas Fases 1 e 3 para ambos os grupos de participantes.

Pré-treino. Os participantes foram instruídos pelo experimentador no desempenho da tarefa com quatro pares de palavras-estímulo em português ('vermelho', 'amarelo', 'azul', 'verde'): diante da palavra-estímulo o participante devia digitar a palavra-resposta correspondente em inglês ('red', 'yellow', 'blue', 'green').

O experimentador mostrava ao participante que quando a palavra-estímulo era apresentada era possível: (a) obter dicas em relação aos caracteres corretos: pressionar a tecla $T A B$ com o cursor sobre um traço produzia naquele traço a letra correta, e (b) obter a palavra-resposta inteira: pressionar a tecla ENTER produzia a palavra-resposta inteira e encerrava a tentativa. Treino - instruçôes gerais e contingências experimentais. Encerrado o pré-treino, o participante lia, na presença do experimentador, as instruçôes (a seguir) apresentadas na tela do computador. As instruções também ficaram disponíveis para o participante na forma impressa:

Sua tarefa é aprender um conjunto de pares de palavras, uma delas em português e a outra em inglês. Uma palavra será apresentada no centro da tela e você deverá digitar a palavra correspondente nos espaços que estão colocados na parte inferior da tela, abaixo da palavra apresentada.

Tabela 1

Pares de palavras treinados nas Fases 1 e 3. As palavras-resposta estão à direita no par em itálico. Nas Fases 2 e 4, de reversão das Fases 1 e 3, respectivamente, as direções de treino IP e PI foram invertidas.

\begin{tabular}{|c|c|c|c|c|}
\hline \multirow[t]{2}{*}{ Fase } & \multicolumn{2}{|c|}{$\begin{array}{c}\text { Grupo } 1 \\
\text { (participantes } 1,2,3,8,9,11)\end{array}$} & \multicolumn{2}{|c|}{$\begin{array}{c}\text { Grupo } 2 \\
\text { (participantes } 4,5,6,7,10)\end{array}$} \\
\hline & PI & IP & $\mathrm{PI}$ & IP \\
\hline \multirow[t]{10}{*}{1} & amora-mullberry & rafter-caibro & caibro-rafter & mullberry-amora \\
\hline & amortecedor-muffler & chive-cebolinha & cebolinha-chive & muffler-amortecedor \\
\hline & ancinho-rake & thimble-dedal & dedal-thimble & rake-ancinho \\
\hline & arado-plow & clutch-embreagem & embreagem-clutch & plow-arado \\
\hline & broca-drill & pallet-enxerga & enxerga-pallet & drill-broca \\
\hline & cabresto-halter & skimmer-escumadeira & escumadeira-skimmer & halter-cabresto \\
\hline & cutia-agouti & skewer-espeto & espeto-skewer & agouti-cutia \\
\hline & jacinto-zircon & otter-lontra & lontra-otter & earwing-lacraia \\
\hline & lacraia-earwing & squid-lula & lula-squid & hare-lebre \\
\hline & lebre-hare & daffodil-narciso & narciso-daffodil & zircon-jacinto \\
\hline \multirow[t]{5}{*}{3} & cascalho-gravel* & boar-javali* & cascalho-gravel* & boar-javali* \\
\hline & cominho-caraway & hatchet-machadinha & machadinha-hatchet & caraway-cominhos \\
\hline & foice-scythe & quince-marmelos & marmelo-quince & cythe-foices \\
\hline & lage-slab & parrow-pardal & pardal-sparrow & lab-laje \\
\hline & morsa-walrus & willow-salgueiro & salgueiro-willow & walrus-morsa \\
\hline
\end{tabular}

\footnotetext{
* Por um erro de programação a ordem do treino dos pares cascalho-gravel e boar-javali foi a mesma para ambos os grupos.
} 
Em cada espaço apenas uma letra poderá ser digitada. As palavras apresentadas poderão ser em inglês e, nesse caso, você deverá digitar a palavra correspondente em português, ou então a palavra será em português e você deverá digitar seu sinônimo em inglês. $\mathrm{O}$ número de espaços disponíveis para você responder é fixo, isto é, independe do número de letras da palavra resposta correta. Responda o mais rápido e corretamente quanto for possível. Quando você terminar de digitar pressione a tecla de espaço. Quando você estiver pronto para mais uma palavra pressione a tecla de espaço novamente. Quando todas as palavras tiverem sido aprendidas você ouvirá um som seguido pela mensagem na tela: "Você chegou ao fim. Por favor, comunique ao pesquisador".

Pressionar a barra de espaço iniciava a tentativa e a primeira palavra era apresentada na tela. Abaixo da caixa de digitação estava presente a instrução: "pressionar a tecla TAB para uma dica ou a tecla ENTER para pular a palavra”.

Digitar a tecla correta ou a tecla TAB revelava a letra correta na tela e movia o cursor um traço (reservado para a letra seguinte na caixa de resposta).

Digitar uma letra incorreta produzia um som, o cursor não se movia e nenhuma mudança ocorria na tela.

Uma tentativa se encerrava quando cinco letras incorretas eram digitadas diante de uma palavra-estímulo, ou quando a última letra da palavra-resposta era digitada e o participante clicava a barra de espaço, encerrando a tentativa.

Se a resposta na tentativa era considerada correta (menos que cinco erros de digitação) aparecia na tela a mensagem "Ótimo!", juntamente com um som, por 0,5 segundos. Se a resposta era considerada incorreta, aparecia a mensagem "Você errou", por 1 segundo, em conjunto com um segundo som.

Digitar ENTER, em qualquer posição que estivesse o cursor, imediatamente apresentava por 1, 3 segundos a palavra-resposta completa, acompanhada da mensagem "Você está pulando esta palavra" e, neste caso, a resposta era considerada incorreta.

Uma nova tentativa se iniciava quando o participante clicava a barra de espaço.

As tentativas foram agrupadas em blocos de 20 pares de palavras nas Fases 1 e 2, e 10 pares de palavras nas Fases 3 e 4 . Em cada fase os blocos continham o mesmo conjunto de palavras, sendo que metade das palavrasestímulo estava em português e a outra metade em inglês (sempre as mesmas na fase). Embora as mesmas palavras-estímulo fossem apresentadas nos sucessivos blocos de uma fase, a ordem das palavras em cada bloco era aleatória e em cada bloco se misturavam as palavras nas duas línguas.

Ao final de cada bloco de tentativas o programa computava: a pontuação alcançada no bloco, a duração das tentativas, o número de palavras completadas, palavras incorretas e percentual de precisão (palavras que foram, ao final, conseqüenciadas com “Ótimo!"). Estas informações também apareciam na tela para o participante por 8 segundos.

Terminado um bloco e encerrada a mensagem, um novo bloco era apresentado. Caso o participante tivesse atingido o critério da fase o bloco seguinte correspondia à nova fase. Exceto pela mensagem ao final dos blocos, o participante não recebia qualquer outra informação que sinalizasse a mudança de bloco ou fase.

Dois critérios de encerramento das fases foram utilizados para diferentes participantes: 
(a) acerto maior ou igual a 75\% no bloco (participantes 1, 2, 3, 4, 5 e 6), ou (b) tempo de exposição à fase (participantes 7, 8, 9, 10 e 11): 10 minutos nas Fases 3 e 4 e 20 minutos nas Fases 1 e 2 . No entanto, na Fase 1, os participantes 7,8 e 9 tiveram 15 minutos adicionais de treino.

Todos os particpantes foram expostos às seguintes condições.

Treino 1 (Fase 1). Nesta condição, 20 respostas intraverbais (ou pares de palavras) foram treinadas: para metade dos pares o estímulo verbal era a palavra em inglês e a resposta verbal era em português (condição IP-1). A outra metade dos pares de palavras foi treinada no sentido contrário: a palavra-estímulo em português e a resposta exigida era uma palavra em inglês (condição PI-1). Blocos sucessivos (com as mesmas palavras em ordem diferente) foram apresentados até o encerramento da Fase.

Reversão 1 (Fase 2). Nesta condição, também chamada de Reversão, os mesmos 20 pares de palavras foram apresentados, mas as direções de treino foram invertidas: ou seja, palavras que haviam sido apresentadas em português no Treino 1 foram apresentadas em inglês e vice-versa. Como no Treino 1, cada palavra foi apresentada uma vez até completar o bloco e os blocos se sucederam (alterandose a ordem de apresentação das palavras) até se atingir o critério de encerramento da sessão. As demais contingências foram idênticas a aquelas já descritas.

Treino 2 (Fase 3). Nesta condição, 10 novas palavras, não treinadas nas fases anteriores, foram apresentadas aos participantes. Cinco palavras foram apresentadas em português exigindo-se como resposta a palavra digitada em inglês (PI-2) e outras cinco foram apresentadas em inglês, exigindo-se como resposta a digitação da palavra em português (IP-2). O procedimento foi o mesmo já descrito.

Reversão 2 (Fase 4). O procedimento nesta conidção foi o mesmo da Reversão 1 , porém as mesmas palavras envolvidas no segundo treino foram utilizadas, invertendo-se a direção do treino (a língua da palavra-estímulo e, conseqüentemente, da palavra-resposta). Os critérios de encerramento foram mantidos.

\section{RESULTADOS}

\section{O desenvolvimento de comportamento intraverbal}

Na Figura 1 são representados os desempenhos de cada um dos participantes em cada condição, sendo que nos seis painéis superiores estão os participantes do Grupo 1 e nos cinco inferiores os participantes do Grupo 2. Foram calculadas as porcentagens de acertos por bloco em cada direção de treino (porcentagem de palavras-resposta corretas em cada apresentação de um bloco de 10 palavras em uma direção de treino no Treino 1 e na Reversão, ou de 5 palavras no Treino 2 e na Reversão 2).

Os desempenhos de todos os participantes foram afetados pelas contingências, ou seja, comportamento intraverbal foi produzido em ambas as direções de treino em todos os participantes e a cada fase menos treino foi necessário.

$O$ procedimento de treino intraverbal aqui utilizado foi efetivo na produção de respostas intraverbais em uma língua quando essas respostas estavam sob controle de estímulos verbais em outra língua. Os treinos de sucessivos grupos de palavras resultaram na aquisição desses operantes intraverbais.

Embora haja oscilações na aquisição de desempenhos precisos, no sentido de haver alguma diminuição de precisão em blocos de treino, em relação a um bloco imediatamente 
anterior, para todos os participantes as curvas indicam um processo de aquisição em que houve, em geral, sistemática diminuição de erros. As exceçôes foram os participantes P2, para quem não houve queda no desempenho entre blocos de uma fase, e P5 (Treino 2) e P6 (Treino 1 e Treino 2), cujos desempenhos mostram grande variação entre sucessivas ten-

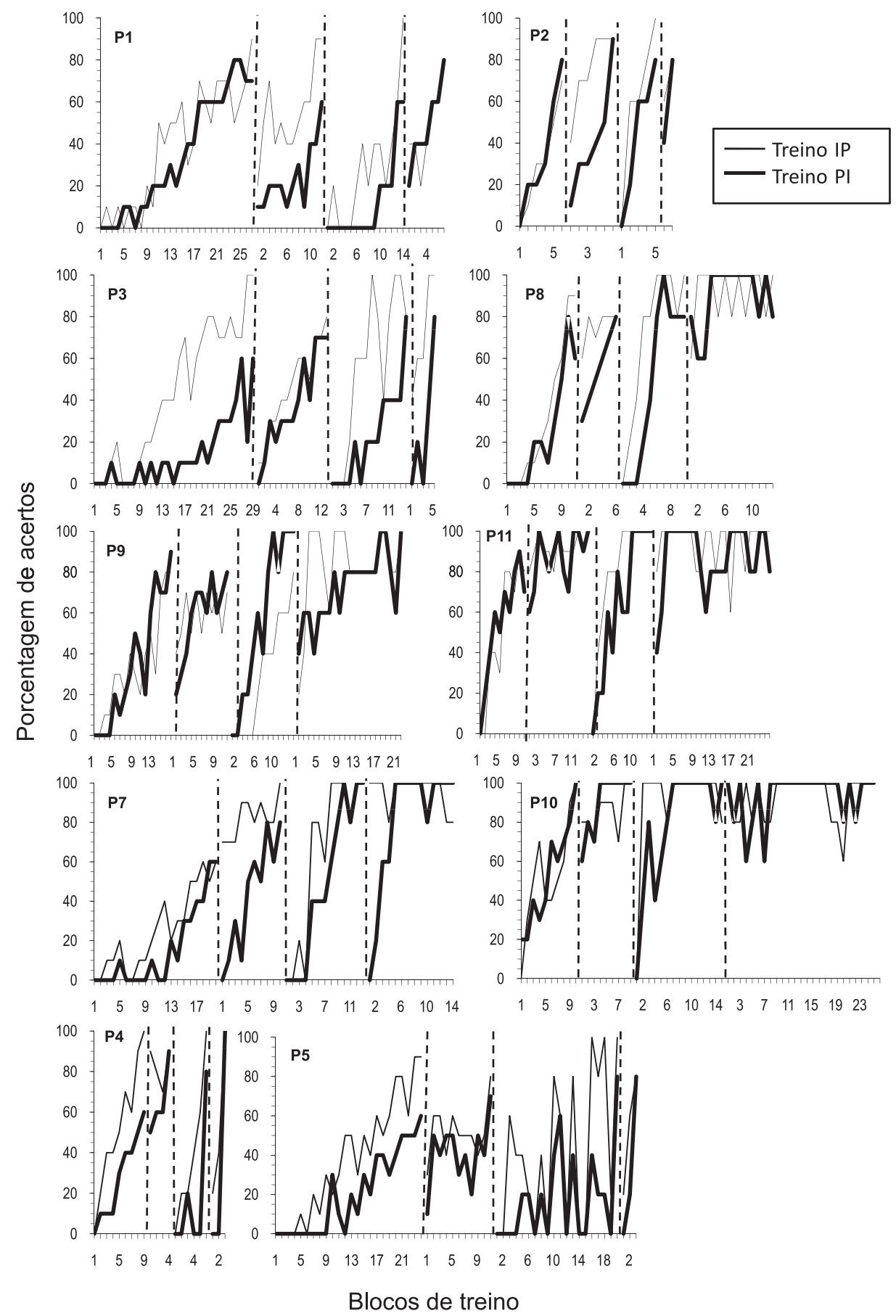

Figura 1. Precisão (\% de acertos) em cada bloco de treino para cada participamte. 
tativas antes de atingirem os critérios de precisão exigidos.

O exame da Figura 1 mostra também que os desempenhos de todos os participantes atingiram altos índices de precisão, ainda que diferentes quantidades de treino tenham sido necessárias para distintos participantes: os participantes que receberam mais treino foram $\mathrm{P} 1 \mathrm{e}$ P3, expostos a 59 blocos de treino (29 e 12 blocos nas duas primeiras condiçôes, e 13 e 5 blocos nas duas últimas) e os participantes para os quais menos treino foi necessário foram $\mathrm{P} 4 \mathrm{e}$ P8 que foram expostos a apenas 19 blocos (6 blocos no Treino 1 e na Reversão 1, 5 blocos no Treino 2 e apenas 2 blocos na Reversão 2).

Houve diferença na aquisição de comportamento intraverbal quando as respostas exigidas envolviam a língua nativa ou a língua estrangeira, ainda que a língua estrangeira não fosse completamente desconhecida dos participantes. $\mathrm{O}$ efeito do procedimento empregado foi mais rápido na direção de treino Inglês-Português.

Os resultados da Figura 1 indicam claramente que a aquisição de comportamento intraverbal envolvendo a relação palavra-estímulo-em-português e palavra-resposta-em-inglês (treino PI) foi mais demorada que a relação inversa (treino IP). Com exceção de quatro blocos no Treino 1 de P1, em todos os demais blocos de todas as fases os desempenhos dos participantes foram igualmente ou mais precisos no treino Inglês-Português (IP) do que foram no treino Português-Inglês (PI). A maior dificuldade do treino na direção PI também se torna visível no desempenho inicial dos participantes no primeiro bloco de treinos PI e IP nas reversões. Com exceção dos participantes P8 e P9 (Grupo 1) e P10 (Grupo 2), em todos os outros casos o desempenho dos participantes foi igual (P4 e P5 tiveram $0 \%$ de acertos no primeiro bloco PI e IP da Fase 4) ou pior no primeiro bloco de treino PI do que no primeiro bloco do treino IP.

A aquisição de operantes intraverbais envolvendo pares de palavras não produziu a emissão de comportamento verbal simétrico ao comportamento treinado sem treino adicional, como indicam os resultados das reversões. A análise da Figura 1 indica que não ocorreu completa e imediata reversibilidade (ou simetria) na emissão de respostas verbais. Ou seja, no primeiro bloco de treinos das Fases 2 e 4, quando as palavras antes apresentadas em Inglês passaram a ser apresentadas em Português e vice-versa, em geral houve uma diminuição na precisão do desempenho em relação aos níveis de precisão do participante na fase anterior.

O exame da Figura 2 permite avaliar a ocorrência ou não do que está sendo chamado de simetria. Cada painel da Figura 2 representa o desempenho dos participantes em uma fase de treino e, neles, cada barra ou triângulo representa o desempenho de um participante. As barras cinzas mostram as porcentagens de acerto no último bloco dos treinos IP e as barras brancas nos treinos PI. Os triângulos representam a porcentagem de acerto no primeiro bloco das reversões, isto é, o treino na direção oposta. No caso de haver emergência imediata de simetria, a altura das barras e dos triângulos seria pelo menos igual. Como indicam suas alturas e as linhas que representam a porcentagem média de acertos para todo o grupo de participantes, houve, em geral, uma diminuição na precisão no bloco inicial das duas fases de reversão, em ambas as direções de treino.

No final do Treino 1 ambos os grupo tinham $88 \%$ de acertos em média, mas no primeiro bloco de Reversão 1 a média de acertos mo treino PI caiu para $21 \%$ no caso dos parti- 
cipantes do Grupo 1 e para 28\% para os participantes do Grupo 2. No final do treino PI a média de acertos entre os participantes dos Grupos 1 e 2 era de $72 \%$ e $75 \%$, respectivamente, mas a média de acertos caiu para $41,6 \%$ e 66\% (Grupos 1 e 2) no início do treino IP na Reversão 1. A média de acertos de cada grupo de participantes, calculada como porcentagem de acertos, no primeiro bloco da Reversão 2 também foi bem menor, tanto nos treinos IP como PI, ainda que a perda de precisão tenha sido menor na reversão de treino PI para IP, como ocorreu na Reversão 1.

Houve, no entanto, algumas exceções indviduais: os participantes P4, P7 e P8 na Fase Reversão 1 e P6, P7 e P10 na Reversão 2 tiveram porcentagem de acertos igual ou maior no primeiro bloco IP das reversões; já o participante P10 foi o único participante a manter precisão na reverssão de IP para PI, na Reversão 2 (100\% de precisão no primeiro bloco de treino PI).
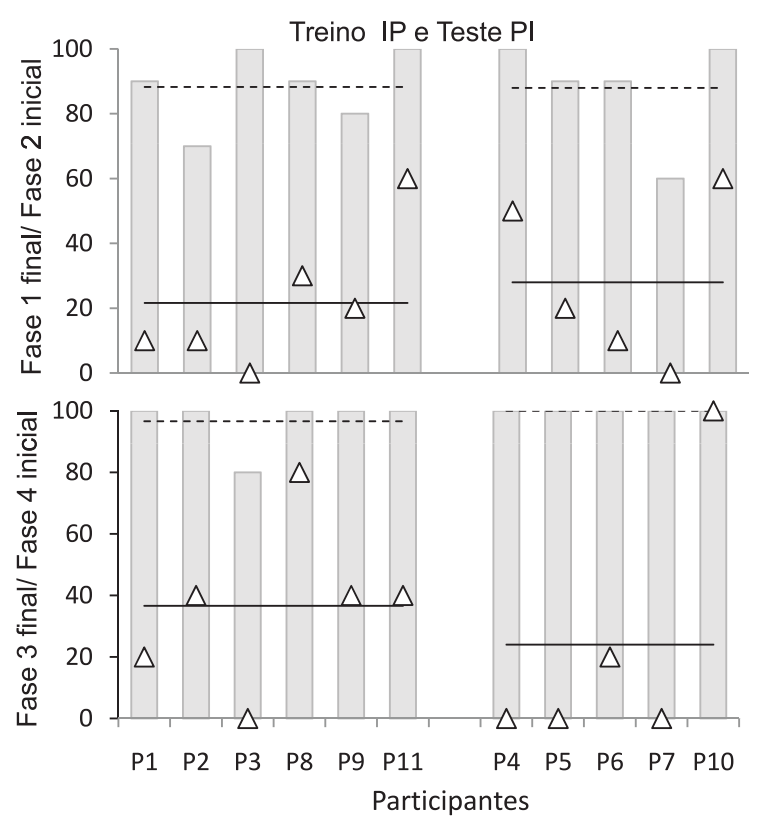

O exame da Figura 1 sugere que a mera exposição ao treino teve efeitos sobre o treino posterior: desempenhos precisos foram obtidos com menos treino nas condições de reversão e menos treino foi necessário no segundo Treino e Reversão do que foi necessário no Treino e Reversão 1. Ainda que estes últimos resultados possam ter sido obtidos em parte porque os conjuntos de palavras eram menores no segundo Treino e Reversão, os desempenhos nas reversões sugerem um efeito do treino anterior. No entanto, o exame da Figura 2 indica que é preciso cautela quando se avalia o ganho em termos de níveis de precisão: a mera exposição ao treino não produziu mais acerto, ou seja, não houve mudança significativa nas porcentagens de acerto nas condições de Treino 2 e reversão 2, especialmente no caso de alguns participantes (P3, P4, P5, P7, P9 e P11 no teste PI, e P4, P5, P8 e P9 no teste IP).

Ainda que os resultados representados nas Figuras 1 e 2 sugiram que os subconjuntos de

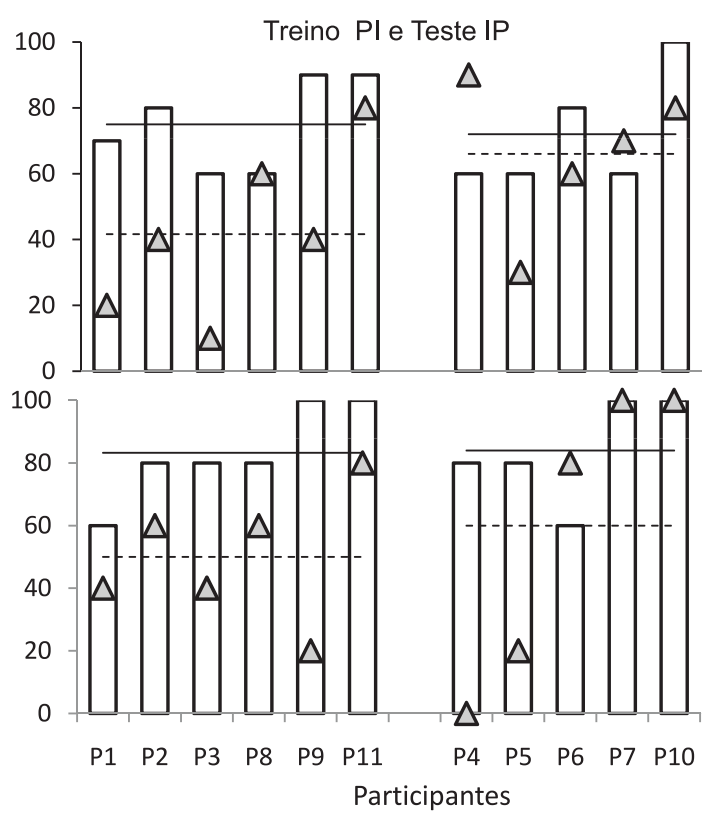

Figura 2. Precisão (\% de acertos) no final das Fases 1 e 3 e nas reversões (Fases 2 e 4 ) em cada direção de treino, por participante. 
palavras treinadas inicialmente com os participantes dos grupos 1 e 2 não tinham dificuldades diferentes, considerou-se importante avaliar os pares de palavras utilizados.

$\mathrm{Na}$ Figura 3 foram somados para cada par de palavras em uma direção de treino os erros e solicitações de dicas de todos os particpantes. As médias de erros e solicitações de dicas foram calculadas considerando-se o subconjunto de palavras designado para cada um dos grupos de participantes (ver Tabela 1). Claramente, o desempenho dos participantes de ambos os grupos foi melhor no segundo Treino e Reversão, indicando um efeito de treino das condições anteriores, ainda que os subconjuntos de palavras fosse completamemte novo. No primeiro Treino e Reversão (Fases 1 e 2) o treino PI para o Grupo 2 produziu mais erros e solicitações de dicas que para o Grupo 1. Este resultado não parece ser devido a diferenças entre os grupos, uma vez que no segundo Treino e Reversão ocorreu o inverso. Como se pode ler na Figura 4, o treino IP foi em geral mais fácil que o treino PI (com exceção dos pares de palavras ancinho-rake e embreagem-clutch), produzido um número semelhante ou menor de erros e solicitações de dicas.
Na Figura 4 são apresentados os erros e solicitação de dicas acumulados em cada tentativa, para cada par de palavras, por fase e direção de treino. Foram somados, na apresentação de uma palavra em cada bloco, o número de letras incorretamente digitadas e o número de solicitações de dicas de todos os particpantes de um grupo. Em cada painel são representados os números acumulados de erros e dicas para um par de palavras e cada curva representa o número acumulado para aquele par em uma direção de treino (PI ou IP) de um grupo de participantes (Grupo 1 ou Grupo 2). Os pares de palavras foram divididos em dois subconjuntos e para cada grupo iniciou-se um subconjuntocom uma direção de treino, assim, cada painel tem quatro curvas (ver Tabela 1). $\mathrm{Na}$ ordem de apresentação dos painéis considerou-se o treino PI do Treino 1 (20 painéis superiores) ou Treino 2 (10 painéis inferiores). $\mathrm{Na}$ Figura 3 foram somados os treinos dos dois grupos em cada direção (PI e IP), mas na Figura 4 estes desempenhos foram separados.

$\mathrm{O}$ exame da Figura 4 confirma em geral os resultados descritos. A Figura 4 permite que se avalie também o efeito da reversão sobre o treino: na condição de Reversão 1 (Fase 2) hou-

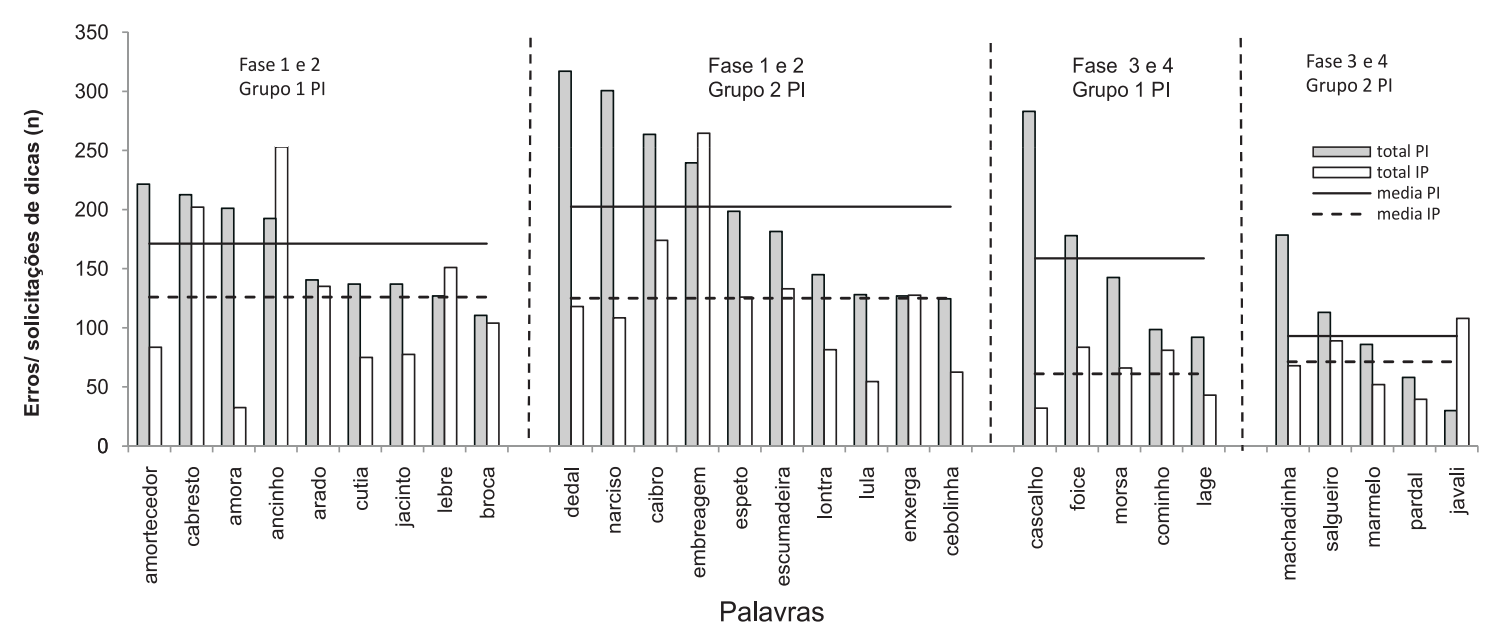

Figura 3. Número de erros e solicitações de auxílio, diante de cada palavra-estímulo, nas duas direções de treino. 


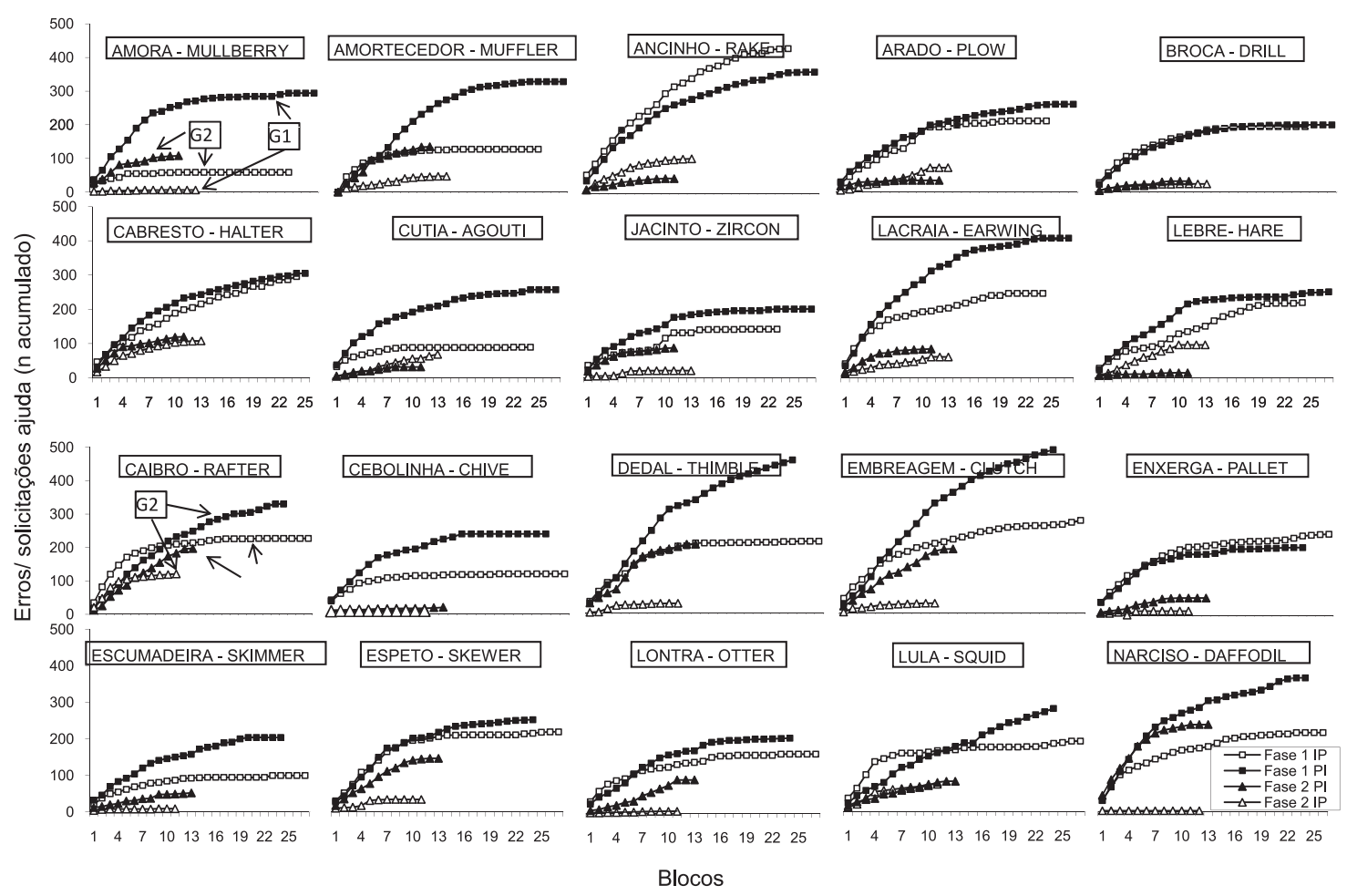

Figura 4. Número de erros e solicitaçôes de auxílio acumulados em cada tentativa, diante de cada palavra-estímulo, nas duas direçôes de treino, a cada bloco de treino.

ve mais erros e solicitações de dica no treino IP diante dos pares ancinho-rake, mas também dos pares arado-plow, cutia-agouti e lebre-hare, sempre envolvendo o Grupo 2. Já na Reversão 2 (Fase 4), o mesmo ocorreu apenas para o par morsa-walrus(Grupo 1). Na Figura 4 está ainda claramente indicado que o procedimento produziu desempenho com pouco ou nenhum erro para todos os pares de palavras e o processo de aquisição em geral foi bastante semelhante especialmente nas Fases 1 e 3 de treino, quando os erros e solicitações de dicas tornam-se sistematicamente menos freqüentes no decorrer dos blocos de treino, até haver estabilização com poucos ou nenhum erro, indicando a aquisição de comportamentos intraverbais que envolvem distintas respostas verbais (escritas) para distintos estímulos verbais (escritos).
Os efeitos dos conjuntos de palavras sobre o desempenho

O exame das Figuras 3 e 4 revela também que os pares de palavras exigiram diferentes quantidades de treino. $\mathrm{Na}$ Fase 1 os pares de palavras ancinho-rake, amortecedor-muffler lacraiaearwing(Grupo 1) e dedal-thimble, embreagemclutch, narciso-daffodile caibro-rafter(Grupo 2) foram os que mais produziram erros/ solicitação de ajuda. Nas reversões (Fases 2 e 4) sempre houve menos erros, mas, em geral, os mesmos pares de palavras que evocaram muitos erros nas fases de treino para um grupo de participantes, evocaram mais erros e solicitaçóes de ajuda nas reversóes do outro grupo, indicando que o resultado se deveu a características dos estímulos e respostas envolvidos e que não são artefatos decorrentes de características dos participantes em cada grupo ou da ordem de treino. 
Este resultado fortalece a hipótese de que outras variáveis, além daquelas relacionadas diretamente ao controle intraverbal, contribuíram para a variabilidade dos resultados. Ainda que se interprete o comportamento verbal que foi resultado do procedimento de treino aqui empregado como comportamento intraverbal, obviamente houve componentes de comportamento textual (as palavras estímulos eram "lidas") e possivelmente também componentes de comportamento de transcrição tipo cópia (as palavras-resposta eram digitadas diante das palavras estímulo). Pode ter havido ainda componentes de comportamento de transcrição tipo ditado (os participantes podiam "dizer " as palavras e escrevêlas) e componentes de outros comportamentos intraverbais além daqueles explicitamente exigidos no treino (por exemplo, os participantes podem ter classificado todos/alguns substantivos, como animais, plantas etc.). Tais componentes são variáveis que podem ter afetado diferentemente os desempenhos dos participantes diante das palavras-estímulo.

Além disso, características topográficas das palavras-estímulo e das palavras-resposta (as letras envolvidas e seu arranjo), tais como a ocorrência de um mesmo subconjunto de letras em um dado subconjunto de palavras, podem ter promovido generalização 'indevida' para outras palavras do subconjunto e podem estar também na origem das diferenças nos desempenhos diante de diferentes palavras

Para avaliar estas possibilidades foram analisados os erros nos treinos de alguns pares de palavras. Optou-se pela análise daqueles pares diante dos quais ocorreram mais erros/solicitações de dicas: amortecedor-muffler, lacraia-earwing, lebrehare, ancinho-rake (Fase 1 para o G1 e Fase 2 para o G2), rake-ancinho, caibro-rafter, dedal-thimble, embreagem-clutch, narciso-daffodil (Fase 1 para G2 e Fase 2 para G1), foice-scythee willow-salgueiro (Fase 3 para G1 e Fase 4 para G2), machadinha-hatchet, salgueiro-willow (Fase 3 para G2 e Fase 4 para G1). Para cada um desses treinos foram listadas todas as teclas digitadas em cada tentativa, sucessivamente, para cada participante. Então, erros e solicitaçôes de auxílio/ dica (TAB), ou de toda a palavra (ENTER) foram analisados em busca de recorrências que pudessem indicar algumas das variáveis responsáveis pelos padrões identificados.

Nas Tabelas 2, 3 e 4 são apresentados exemplos da análise para algumas palavras e alguns participantes. Cada coluna corresponde a um treino para um participante e cada linha a seu desempenho em uma tentativa. Cada resposta de digitação do participante é representada com as letras erradas em minúsculo e negrito; as solicitações de dicas como sinais de menos (-) que são seguidos das letras apresentadas ao participante entre parêntesis em negrito; e a solicitação da palavra inteira aparece como sinal de interrogação seguido da palavra entre parêntesis em negrito. As letras maiúsculas representam respostas corretas de digitação.

De início foram identificados padrões de erros que sugerem apenas a variabilidade que é típica quando respostas não produzem reforçamento, ou seja, padrōes de respostas que não dependiam de características específicas das palavras-estímulo ou palavras-respostas, mas sim de características do procedimento ou equipamento: por exemplo, nos treinos iniciais havia maior probabilidade de solicitação de dicas ou da palavra inteira e de erros que consistiam de uma seqüência de vogais depois de uma consoante, ou seqüências de digitações na ordem em que as letras estão dispostas no teclado (QWERT). Estes erros, no entanto: (a) tende- 
ram a ocorrer menos nas reversões, (b) tenderam a diminuir rapidamente no decorrer das sucessivas apresentações de uma palavra-estímulo (c) não foram freqüentes para a maior parte dos participantes.

A análise mostrou, no entanto, que alguns outros padrões de erros e solicitações de auxílio foram recorrentes entre os participantes nos treinos. Tais padróes tenderam a ocorrer nas Fases 1 e 3 (treinos) e nas suas reversões (Fases 2 e 4). Quando não houve simetria, foi comum que os participantes apresentassem, nas fases de reversão, os mesmos padrões de erros encontrados no treino da palavra para os participantes do outro grupo, na fase anterior. Ou seja, em geral os erros nas reversões tiveram as mesmas características dos erros nos treinos iniciais, mas ocorreram com menor frequência.

Um padrão de erros e solicitação de auxílio que sugere controle típico de comportamento de transcrição e que ocorreu com todos os participantes e em vários treinos analisados é exemplificado na Tabela 2. Neste caso, no início do treino, o participante solicitava auxílio e dicas letra a letra, mas na medida em que o treino prosseguia passava a responder independentemente de dicas, do final para o começo da palavra. Tal padrão foi interpretado como indicativo do estabelecimento de controle semelhante a aquele que ocorre na transcrição em que partes do estímulo correspondem a partes da resposta: as respostas dos participantes parecem ter ficado sob controle de unidades cada vez mais extensas da palavra-estímulo e cada componente da palavra se estabeleceu como estímulo discriminativo que evocava o componente seguinte. Uma variação deste padrão, comum nos treinos IP (por exmplo, rakeancinhoe willow-salgueiro), envolveu, desde o início do treino, a emissão de conjuntos de letras (nhoou inho, eiroou gueiro) comuns na língua portuguesa, que pareciam funcionar como uma unidade: digitar o início da palavra evocava a digitação de todo o conjunto seguinte, daí, em parte, a menor dificuladde do treino IP (ver também P10 na Tabela 2 e P)

Tabela 2

Desenvolvimento do comportamento intraverbal com componentes de comportamento de transcrição.

O sinal de menos representa solicitação de dicas e o sinal de interrogação a solicitação da palavra.

Letras/ palavras entre parêntesis são aquelas apresentadas pelo computador. As letras minúsculas representam letras erradas digitadas pelo participante e as letras maiúsculas as letras corretas.

\begin{tabular}{|c|c|c|c|}
\hline Tent & $\begin{array}{c}\text { amortecedor } \rightarrow \text { muffler } \\
\text { P9, Fase } 1\end{array}$ & $\begin{array}{c}\text { rake } \rightarrow \text { ancinho } \\
\text { P10, Fase } 1\end{array}$ & $\begin{array}{c}\text { foice } \rightarrow \text { scythe } \\
\text { P2, Fase } 3 \\
\end{array}$ \\
\hline 1 & $-(\mathrm{M})-(\mathrm{U})-(\mathrm{F})-(\mathrm{F}) \mathrm{L}$ E R & ? (MUFFLER) & $-(\mathrm{S})-(\mathrm{C})-(\mathrm{Y})-(\mathrm{T})-(\mathrm{H}) ?(\mathrm{SCYTHE})$ \\
\hline 2 & $-(\mathrm{M})-(\mathrm{U})-(\mathrm{F})-(\mathrm{F}) \mathrm{L}$ E R & -(A) -(N) aeiou ? (MUFFLER) & $-(\mathrm{S})-(\mathrm{C})-(\mathrm{Y}) \mathrm{d}-(\mathrm{T}) \mathrm{H}$ yi -(E) \\
\hline 3 & -(M) -(U) F F L E R & $-(\mathrm{A})-(\mathrm{N})-(\mathrm{C})$ ora $?$ & $S-(\mathrm{C}) \mathrm{h}-(\mathrm{Y}) \mathrm{T} \mathrm{H} \mathrm{E}$ \\
\hline 4 & $-(\mathrm{M})-(\mathrm{U}) \mathrm{F} F \mathrm{~L}$ r E e R e & $-(\mathrm{A})-(\mathrm{N})-(\mathrm{C})$ orao ? & S Ch -(Y) T H E \\
\hline 5 & -(M) -(U) F F L E R & $-(\mathrm{A})-(\mathrm{N}) \mathrm{C}$ ora I N H O & SCYTHE \\
\hline 6 & -(M) U F F L E R & -(A) N C I N H O & \\
\hline 7 & $-(\mathrm{M}) \mathrm{U} F \mathrm{~F}$ L E R & -(A) N C h I N H O & \\
\hline 8 & -(M) U F F L E R & -(A) N C I N H O & \\
\hline 9 & dd -(M) U F F e L E R & A NCINHO & \\
\hline 10 & MUFFLER & A N C INHO & \\
\hline
\end{tabular}


na Tabela 4). Estes padrōes indicam, então, claramente, que o treino envolveu componentes de comportamento intraverbal e também de transcrição. Como resultado, parte da dificuldade ou facilidade de um dado treino decorreu de características do comportamento de transcrição envolvido.

Outro padrão identificado, mais freqüente na direção de treino PI, foi interpretado como decorrência de controle conjunto de comportamento textual e de transcrição. Os participantes erravam digitando letras que formavam conjuntos em outras palavras já treinadas, ou que estavam sendo treinadas. $\mathrm{Na} \mathrm{Ta}-$ bela 3, são listados exemplos desses desempenhos, comuns quando as palavras-resposta corretas eram hare, rake, rafterou halter, algumas delas treinadas no mesmo subconjunto. Estas são palavras semelhantes (especialmente para um falante nativo de português): são palavras dissílabas, com as mesmas duas vogais na mesma ordem e que começan com $r$ ou $h$, duas letras que tendem a ser "ditas" por falantes brasileiros com sons semelhantes quando lidas em "inglês" $(r a)$. Estas características provavelmente produziram os erros listados: $r /$ re (hare) e $f t$ $f$ (rafter) apareceram na digitação de rake, $l$ (halter), k/ke (rake), re (hare) apareceram na

Tabela 3

Desenvolvimento do comportamento intraverbal com componentes de comportamento de transcrição e de comportamento textual - generalização entre palavras treinadas. O sinal de menos representa solicitação de dicas e o sinal de interrogação a solicitação da palavra. Letras/ palavras entre parêntesis são aquelas apresentadas pelo computador. As letras minúsculas representam letras erradas digitadas pelo participante e as letras maiúsculas as letras corretas.

\begin{tabular}{|c|c|c|c|c|}
\hline Tent & $\begin{array}{c}\text { ancinho } \rightarrow \text { rake } \\
\text { P1, Fase } 1\end{array}$ & $\begin{array}{c}\text { lebre } \rightarrow \text { hare } \\
\text { P2, Fase } 1\end{array}$ & $\begin{array}{c}\text { caibro } \rightarrow \text { rafter } \\
\text { P3, Fase } 2 \\
\end{array}$ & $\begin{array}{c}\text { foice } \rightarrow \text { scythe } \\
\text { P9, Fase } 3\end{array}$ \\
\hline 1 & ? (RAKE) & $s-(\mathrm{H})-(\mathrm{A}) \mathrm{lfb}-(\mathrm{R}) \mathrm{r} E$ & -(R) A k l -(F) T E R & -(S)-(C)-(Y)-(T)er-(H)er \\
\hline 2 & R A re KE & $-(\mathrm{R})-(\mathrm{A}) 1 \mathrm{R} E$ & -(R) A ke r l-(F) T h E R r & $-(S)-(\mathrm{C})-(\mathrm{Y})-(\mathrm{T}) \operatorname{HEr}-(-)$ \\
\hline 3 & RAKE & -(R) Al R E & -(R) A k r l-(F) fe T E R & $-(\mathrm{S})-(\mathrm{C})-(\mathrm{Y}) \mathrm{ce}-(\mathrm{T}) \mathrm{er}-(\mathrm{H})$ \\
\hline 4 & h RArKE & -(R) A le R E & c -(R) A 1 F fT E R & $-(S)-(C) h-(Y) c-(T) H E$ \\
\hline 5 & RA r KE & -(R) A R E & $-(\mathrm{R})$ A re ke & $-(\mathrm{S}) \mathrm{q}-(\mathrm{C}) \mathrm{Y}-(\mathrm{T}) \mathrm{cH}-(\mathrm{E})-(-) \mathrm{er}$ \\
\hline 6 & h RAre KE & -(R) A l k R E & h-(R)Arkel-(F) f-(T) ER & -(S) s-(C) YT ce H E \\
\hline 7 & e a R t K E & & -(R) A k r l-(F) f T E R & -(S) -(C) YT cer H E \\
\hline 8 & RArKE & & -(R) A FT E R & SCYT er HE er \\
\hline 9 & & & -(R) A F T E R & SCYTHE \\
\hline
\end{tabular}

P7, Fase 2

P2, Fase 2

1 RAKE

2 RAtKfE

3 RAKE

4 RAKE

5 RAftKE

6 RAKE

-(R) A ke -(F) T E e R r

-(R) A k 1 -(F) f T E R

-(R) A ke l-(F) f T E R

h -(R) A F f T E R

-(R) A k F T E R 
digitação de rafter; l (halter) e k/ke (rake) digitação de hare. semelhante (Tabela 3) deve ter operado na digitação da sílaba er (possivelmente como generalização de rafter, skimmer, skewer, otter) no final de palavras curtas, como clutch, scythe, ou thimble (mas não de palavras mais longas como daffodil earwing).

Ainda um outro efeito conjunto de comportamento de transcrição e textual parece ter ocorrido com erros que foram comuns quando a palavra-resposta na língua inglesa tinha encontros consonantais e/ou letras incomuns na língua portuguesa: $t c h$ (hatchetou $c l u t c h$ ); ff(daffodilou muffler); ffl (muffler); mbl(thimble); ou, ainda, scy (scythe). Na Tabela 4 alguns exemplos são apresentados: nos treinos das palavras-resposta muitos erros e solicitações de ajuda ocorreram exatamente na sílaba com encontro de letras incomum na língua portuguesa, sugerindo que parte da resposta emitida estava ainda sob controle de estímulos que fora desenvolvido como comportamento textual e/ou de transcrição em português (ver também Tabela 2, foice-scythe). Possivelmente o mesmo ocorreu nos erros de P9 com a palavra salgueiro (ver Tabela 4).

Finalmente, pareceu importante destacar como mais um caso de controle de estímulos estabelecido no treino, que se generalizou para outros treinos, os erros nas primeiras letras das palavras treinadas. O destaque é importante porque, neste caso, o controle de estímulos incorreto deveu-se ao conjunto de palavras escolhido. Freqüentemente, os participantes digitavam como primeira letra aquela correspondente a outra palavra do grupo naquela fase: por exemplo, como se pode ver na Tabela 3, P1, P2 e P3 digitaram h(hare) em vez de $r$, nos casos de rakee raftere $\mathrm{P} 1$ digitou também ea(earwing) em vez de hpara hare.
Na direção de treino PI, o mesmo ocorreu com as palavras clutch thimble, quando os participantes freqüentemente iniciavam a tentativa $\operatorname{com} s$, uma letra que iniciava muitas palavras do conjunto (skimmer, skewer, squid). Já na direção de treino IP, nos dois treinos analisados este foi um erro muito comum, provavelmente devido ao controle de transcrição e intraverbal já existente por unidades mínimas maiores, no caso de palavras-resposta em português. Nestes casos, depois da primeira letra ou sílaba, o restante da palavra era evocado como uma unidade: por exemplo, quando a palavra-resposta correta era ancinhoforam comuns as tentativas iniciadas por ar (arado), am (amortecedor), ca (cabresto), ou lllella (lebre lacraia). Quando a palavra-resposta correta era salgueiro (ver P9 na Tabela 4) foi erro comum para muitos participantes iniciar a palavra com m/ma (machadinhal marmelo), p/pa (pardal), ou j/ja (javali).

\section{DISCUSSÃO}

Houve um claro efeito do treino tanto sobre os pares de intraverbais quando estes eram revertidos, mesmo ocorrendo queda no desempenho quando se iniciava as reversóes, como sobre treinos posteriores com novos pares de palavras: assim como os resultados encontrados por Polson e cols. (1997), os dados mostraram uma aquisição de intraverbais mais rápida na condição de reversão (Fases 2 e 4 ) e no segundo treino e reversão (Fases 3 e 4).

Além disso, os resultados mostraram que ainda que os participantes tivessem pouco ou nenhum conhecimento anterior de inglês seus desempenhos mudaram drasticamente com um treino curto, que durou no máximo $100 \mathrm{mi}-$ nutos, no caso do participante P8. 
Polson e cols. (1997) sugeriram que em novos estudos fossem analisados os desempenhos em relação às das palavras envolvidas nos treinos e os erros cometidos. No presente estudo se iniciou esta análise que, de fato, mostrou-se produtiva, indicando que parte da " $\mathrm{di}$ ficuldade" no estabelecimento da relação intraverbal - e de sua reversibilidade, possivelmente - deveu-se a aspectos relacionados às palavras selecionadas para o treino e à história pré-experimental dos participantes com os estímulos e as respostas.

Além de contribuir para a compreensão do estabelecimento de intraverbais e de ter in-

Tabela 4

Desenvolvimento do comportamento intraverbal com componentes de comportamento de transcrição e de comportamento textual - efeitos de encontros de letras incomuns. O sinal de menos representa solicitação de dicas e o sinal de interrogação a solicitação da palavra. Letras/ palavras entre parêntesis são aquelas apresentadas pelo computador. As letras minúsculas representam letras erradas digitadas pelo participante e as letras maiúsculas as letras corretas.

\begin{tabular}{|c|c|c|c|}
\hline Tent & $\begin{array}{c}\text { embreagem } \rightarrow \text { clutch } \\
\text { P1, Fase } 2\end{array}$ & $\begin{array}{c}\text { amortecedor } \rightarrow \text { muffler } \\
\text { P3, Fase } 1\end{array}$ & $\begin{array}{c}\text { willow } \rightarrow \text { salgueiro } \\
\text { P9, Fase } 3\end{array}$ \\
\hline 1 & C L U - (T) n - (C) -(H) -(-) in & ? (MUFFLER) & $-(\mathrm{S})-(\mathrm{A})-(\mathrm{L})-(\mathrm{G})$ aa $-(\mathrm{U})-(\mathrm{E}) \mathrm{dt}$ \\
\hline 2 & ?(CLUTCH) & $-(\mathrm{M})-(\mathrm{U})-(\mathrm{F})-(\mathrm{F})-(\mathrm{L})-(\mathrm{E})-(\mathrm{R})$ & -(S) -(A) L G U -(E) I R O \\
\hline 3 & $-(\mathrm{C})-(\mathrm{L})-(\mathrm{U})-(\mathrm{T})$ th $-(\mathrm{C}) \mathrm{H}$ in $-(-)$ & $-(\mathrm{M})-(\mathrm{U})-(\mathrm{F})-(\mathrm{F})-(\mathrm{L})-(\mathrm{E})-(\mathrm{R})$ & -(S) -(A) L G U E I R O \\
\hline 4 & C L U -(T) tt -(C) -(H) -(-) & -(M) ?(MUFFLER) & $-(\mathrm{S})-(\mathrm{A}) \mathrm{L}$ G U E I R O \\
\hline 5 & $-(\mathrm{C})-(\mathrm{L})-(\mathrm{U})-(\mathrm{T})-(\mathrm{C}) \mathrm{H}$ in $-(-)-(-)$ & $-(\mathrm{M})-(\mathrm{U})-(\mathrm{F})-(\mathrm{F})-(\mathrm{L})-(\mathrm{E})-(\mathrm{R})$ & -(S) -(A) L G U E I R O \\
\hline 6 & CLoUThi-(C) H in -(-) -(-) & $-(\mathrm{M})-(\mathrm{U})-(\mathrm{F})-(\mathrm{F})$ & -(S) A L G UE I R O \\
\hline 7 & CLo-(U) T-(C) H & $-(\mathrm{M})-(\mathrm{U})-(\mathrm{F})-(\mathrm{F})$ e $\mathrm{R}-(\mathrm{F}) \mathrm{e}$ & -(S) A L G UE I R O \\
\hline 8 & C Lo $-(\mathrm{U}) \mathrm{Th}$ in $-(\mathrm{C})-(\mathrm{H})-(-)$ & $-(\mathrm{M})-(\mathrm{U})-(\mathrm{F})-(\mathrm{F}) \mathrm{L}$ E R & $\mathrm{p}-(\mathrm{S}) \mathrm{A}$ L G e U E I RO \\
\hline 9 & $\mathrm{~L}-(\mathrm{C})-(\mathrm{L})-(\mathrm{U})-(\mathrm{T})-(\mathrm{C})-(\mathrm{H}) \mathrm{h}$ & $-(\mathrm{M})-(\mathrm{U})-(\mathrm{F})-(\mathrm{F})-(\mathrm{L}) \mathrm{l}-(\mathrm{E})-(\mathrm{R})$ & p-(S) A L G e U R I E I R O \\
\hline 10 & C L owi-(U) T C H & -(M) -(U) -(F) -(F) L -(E) -(R) & -(S) A L Ge UrE I RO \\
\hline 11 & CLUT-(C) tHt-(-) h & $-(\mathrm{M})-(\mathrm{U})-(\mathrm{F})-(\mathrm{F})-(\mathrm{L})-(\mathrm{E}) 1 \mathrm{R}$ er & ma m-(S) A L Ge U r E I R O \\
\hline 12 & $-(\mathrm{C})-(\mathrm{L})-(\mathrm{U}) \mathrm{T}$ C H & $-(\mathrm{M})-(\mathrm{U})-(\mathrm{F}) \mathrm{F}-(\mathrm{L})-(\mathrm{E}) \mathrm{R}$ & m -(S) A L G UE I RO \\
\hline 13 & C L U - (T) thin - (C) H & $-(\mathrm{M})-(\mathrm{U})-(\mathrm{F})-(\mathrm{F})$ e L E R & mSALGeUEIRO \\
\hline 14 & & $-(\mathrm{M})-(\mathrm{U})-(\mathrm{F}) \mathrm{F}-(\mathrm{L})-(\mathrm{E}) \mathrm{R}$ & maSALGUEIRO \\
\hline 15 & & $-(\mathrm{M})-(\mathrm{U})-(\mathrm{F}) \mathrm{F}-(\mathrm{L})-(\mathrm{E}) \mathrm{R}$ & dSALGUEIRO \\
\hline 16 & & $-(\mathrm{M})-(\mathrm{U}) \mathrm{F} F-(\mathrm{L}) \mathrm{E}$ R & SALGUEIRO \\
\hline 17 & & $-(\mathrm{M})-(\mathrm{U})-(\mathrm{F}) \mathrm{F}$ L E R & \\
\hline 18 & & $-(\mathrm{M}) \mathrm{U} F \mathrm{~F}$-(L) -(E) R & \\
\hline 19 & & $-(\mathrm{M})-(\mathrm{U})$ F F LiE R & \\
\hline 20 & & $-(\mathrm{M})-(\mathrm{U}) \mathrm{F} F \mathrm{~L}-(\mathrm{E}) \mathrm{R}$ & \\
\hline 21 & & -(M) UFFLiER & \\
\hline 22 & & MUFFLER & \\
\hline 23 & & rur-(M) UFF LER & \\
\hline 24 & & MUFFLER & \\
\hline
\end{tabular}


duzido ao exame de aspectos relacionados com controle de estímulos (como a generalização), a análise da precisão nos desempenhos permitiu que se identificasse a ocorrência de diferentes aspectos relacionados ao comportamento verbal dos participantes. Para a maioria dos participantes, a solicitação de dicas foi utilizada como estratégia para o estabelecimento do intraverbal já que no início dos treinos ( $\mathrm{Fa}-$ ses 1 e 3), quando palavras novas eram apresentadas, mais dicas foram solicitadas do que erros cometidos. A dica que poderia ser de uma letra ou a palavra completa servia como modelo para o participante e parece ter sido utilizada como uma estratégia de aprendizagem, já que o participante produzia inicialmente os estímulos para emissão dos intraverbais textual, cópia e ditado. $\mathrm{O}$ uso das dicas tendeu a ser substituído pela redação da palavra pareada com a correspondente ocorrência de erros no decorrer das fases, como se o participante escolhesse se submeter a um processo de modelagem como estratégia de aprendizagem, uma vez que alguma parte da resposta exigida tivesse sido aprendida.

As tarefas envolvidas nos treinos do presente estudo promoveram comportamentos intraverbais, mas envolveram também o controle de outras variáveis, especialmente variáveis relacionadas com outros operantes verbais, como comportamento de transcrição (ditado e cópia) e comportamento textual. A análise dos erros foi reveladora em relação a esta questão: 0 conjunto de palavras que mais evocou erros sugere (como já se comentou) que, de fato, há sutilezas no controle de estímulos, no que se refere ao conjunto de letras que compõem as palavras utilizadas nos treinos que são relevantes para os resultados: por exemplo, uma seqüência de letras já fortalecida pelo reforçamento pode evocar respostas erradas, diante de um estímulo quase desconhecido.

Por outro lado, a exigência de respostas que envolviam arranjos de letras desconhecidos, ou considerados incorretos na língua portuguesa (portanto correlacionados com histórias de reforçamento que tornaram sua emissão pouco provável) também contribuiu para a imprecisão. Casos em que as palavras de um conjunto tinham semelhanças topográficas tanto na direção de treino IP quanto na direção reversa PI (espeto-skewer e escumadeira skimmer; ou amora-mullberry e amortecedor muffler; ou caibro-rafter e cabresto-halter) possivelmente aumentaram ainda mais a dificuldade de estabelecimento de controle de estímulos preciso, ou as possibilidades de controle de estímulos deficitários.

Como parte do treino dos pares intraverbais envolveu a digitação de seqüências de letras que compunham a palavra, supõe-se que as similaridades topográficas e $o$ possível pertencimento de distintas palavras a uma só classe de estímulos, (por exemplo, ferramentas, animais, flores) também podem ter tornado o treino intraverbal mais extenso. Para outras palavras, ainda, é possivel que parte da imprecisão estivesse relacionada com a grafia destas palavras em inglês, uma vez que elas envolviam encontros consonantais e/ ou letras pouco familiares ao falante de língua portuguesa.

Assim, além de questôes relacionadas com a simples generalização, variáveis associadas diretamente com comportamentos textuais e de transcrição já instalados e evocados por estímulos semelhantes a aqueles presentes no treino parecem ter desempenhado importante papel no desempenho dos participantes. Muitas vezes, parece que desempenhos já fortalecidos ti- 
veram que ser enfraquecidos para que o comportamento intraverbal se tornasse preciso. Esta análise parece heurística e pode ser útil em novos estudos sobre a produção de comportamento verbal, especialmente nos casos dos operantes verbais em que as respostas estão sob controle de estímulos antecedentes verbais (ecóico, textual, transcrição e intraverbal).

Finalmente, Polson e cols. (1997) perguntaram em seu estudo se haveria, na condição de reversão, o que eles chamaram de simetria: o participante seria capaz de diante da palavra na língua francesa emitir uma resposta intraverbal na língua inglesa sem qualquer treino adicional. Seus resultados foram semelhantes aos do presente estudo, uma vez que sistematicamente havia queda na precisão no início das reversões, mas também as fases de reversão eram mais curtas. No entanto, não apresentaram resultados individuais. Já no presente estudo, a análise dos desempenhos individuais indicou que houve simteria, mas apenas no caso de alguns participantes. A simetria, entretanto, foi mais fácil quando se passou do treino PI para o treino IP, sugerindo mais uma vez que a construção da resposta ficou sob controle de outras variáveis além da mera apresentação da palavra-estímulo e do conjunto de palavras-estímulo de uma fase. Polson e cols. sugeriram que a simetria dependeria da familiaridade das palavras definidas como estímulos e respostas e consideraram familiaridade como sendo o treino/ ausência de treino do participante. A análise feita no presente estudo sugere que o termo ' $\mathrm{fa}$ miliaridade' é rótulo que pode ser substituído pela análise mais detalhada de variáveis que participam do controle das respostas verbais emitidas a cada tentativa.

De qualquer maneira, a constatação de que a simetria não emerge necessariamente como produto do treino intraverbal não deveria ser surpresa do ponto de vista das afirmações feitas por Skinner, já em 1957. Em relação a comportamento intraverbal, Skinner salienta que nesse operante um estímulo verbal se estabelece como estímulo discriminativo evocando uma resposta verbal específica; e nada indicaria que necessariamente a resposta se tornaria, por sua vez, estímulo discriminativo controlando novos comportamentos intraverbais, mesmo aqueles que envolveriam respostas que têm a mesma topografia do estímulo discriminativo. Ou seja, não se deveria esperar necessariamente reversibilidade no comportamento intraverbal. Os resultados do presente estudo confirmam essa análise e ao mesmo tempo sugerem que tal reversibilidade pode ser obtida em certas condiçōes: especialmente, parece, com treino anterior que produz mais comportamento intraverbal. Este resultado não é diferente de outros encontrados na literatura sobre independência funcional dos operantes verbais (por exemplo, Lamarre \& Hollland, 1985) que sugerem que com a aquisição de repertórios maiores e mais complexos de certos operantes verbais a reversibilidade de início não obtida, passa a ser esperada.

Futuros estudos são necessários para continuar a investigar os efeitos da participação de variáveis controladoras de outros comportamentos sobre a aquisição e a reversibilidade do comportamento intraverbal. A presente análise sugere que algumas manipulações poderiam afetar de maneira significativa os resultados do treino, como, por exemplo, a exigência de emissão de comportamento textual manifesto diante das palavras-estímulo e/ou das palavras-resposta, ou a exigência de emissão de outros comportamentos intraverbais, como a classificação. 


\section{REFERÊNCIAS}

Andery, M. A. P. A. (2001). Notas para uma revisão sobre comportamento verbal. Em H. J. Guilhardi, M. B. Madi, P. P. Queiroz, \& M. C. Scoz (Orgs.). Sobre Comportamento e Cognição: Expondo a Variabilidade (pp. 372-386). Santo André, SP: ESETec. Andery, M. A. P. A., \& Sério, T. M. A. P. (2003). Comportamento verbal. Em M. A. P. A. Andery, T. M. A. P. Sério, \& N. Micheletto (Orgs.). Controle de Estimulos e Comportamento Operante (pp. 113-138). São Paulo: EDUC.

Arntzen, E., \& Almas, I. K. (2002). Effects of mandtact versus tact-only training on the acquisition of tacts. Journal of Applied Behavior Analysis, 35, 419422.

Baer, R. A., \& Detrich, R. (1990). Tacting and manding in correspondence training: Effects of child selection of verbalization. Journal of the Experimental Analysis of Behavior, 54, 23-30.

Bennett, C.W., \& Ling, D. (1972). Teaching a complex verbal response to a hearing impaired girl. Journal of Applied Behavior Analysis, 5, 321-327.

Bourret, J., Vollmer, T. R., \& Rapp, J. T. (2004). Evaluation of a vocal mand assessment and vocal mand training procedures. Journal of Applied Behavior Analysis, 37, 129-144.

Braam, S. J., \& Poling, A. (1983). Development of intraverbal behavior in mentally retarded individuals through transfer of stimulus control procedures: Classification of verbal responses. Applied Research in Mental Retardation, 4, 279-302.

Chase, P. N., Johnson, K. R., \& Sulzer-Azaroff, B. (1985). Verbal relations within instruction: Are there subclasses of the intraverbal? Journal of the Experimental Analysis of Behavior, 43, 301-313.

Garcia, E. (1974). The training and generalization of a conversational speech form in nonverbal retardates. Journal of Applied Behavior Analysis, 7, 137-149.

Hall, G., \& Sundberg, M. L. (1987). Teaching mands by manipulating conditioned establishing operations. The Analysis of Verbal Behavior, 4, 41-54.

Hübner, M. M. C. (2003). Comportamento verbal e não-verbal: efeitos do reforçamento de tactos com autoclíticos referentes ao ler sobre o tempo dispendido com leitura. Em H. M. Sadi, N. M. S. Castro (Orgs.). Ciência do comportamento - conhecer e avançar (pp. 163-173). Santo André, SP: ESETec.

Lamarre, J., \& Holland, J. G. (1985). The functional independence of mands and tacts. Journal of the Experimental Analysis of Behavior, 43, 5-19.

Lee, V. L., \& Sanderson, G. M. (1987). Some contingencies of spelling. The Analysis of Verbal Behavior, 5, 1-13.

Luciano, M. C. (1986). Acquisition, maintenance, and generalization of productive intraverbal behavior through transfer of stimulus control procedures. Applied Research in Mental Retardation, 7, 1-20.

Michael, J. (1984). Verbal behavior. Journal of the Experimental Analysis of Behavior, 42, 363-376.

Michael, J. (1985). Two kinds of verbal behavior plus a possible third. The Analysis of Verbal Behavior, 3, 14.

Michael, J. (1998). The current status and future directions of the analysis of verbal behavior: Comments on the comments. The Analysis of Verbal Behavior, 15, 157-161.

Murphy, C., Barnes-Holmes, D., \& Barnes-Holmes, Y. (2005). Derived manding in children with autism: Synthesizing Skinner's 'Verbal Behavior' with relational frame theory. Journal of Applied Behavior Analysis, 38, 445-462.

Normand, M. P., Fossa, J. F., \& Poling, A. (2000). Publication trends in The Analysis of Verbal Behavior: 1982-1998. The Analysis of Verbal Behavior, 17, 167-173.

Oah, S., \& Dickinson, A. M. (1989). A review of empirical studies of verbal behavior. The Analysis of Verbal Behavior, 7, 53-68.

Partington, J. W. \& Bailey, J. S. (1993). Teaching 
intraverbal behavior to preschool children. _The Analysis of Verbal Behavior, 11, 9-18.

Petursdottir, A. I., Carr, J. E., \& Michael, J. (2005). Emergence of mands and tacts of novel objects among preschool children. The Analysis of Verbal Behavior, 21, 59-74.

Polson, D. A., Grabavac, D. M., \& Parsons, J. A. (1997). Intraverbal stimulus-response reversibility: fluency, familiarity effects, and implications for stimulus equivalence. The Analysis of Verbal Behavior, 14, 19-40.

Richelle, M. (1976). Formal analysis and functional analysis of verbal behavior: Notes on the debate between Chomsky and Skinner, Behaviorism, 4, 209-221.

Ribeiro, A. (1989). Correspondence in children's selfreport: Tacting and manding aspects. Journal of the Experimental Analysis of Behavior, 51, 361-367.

Sautter, R. A., \& LeBlanc, L. (2006). Empirical applications of Skinner's analysis of verbal behavior with humans. The Analysis of Verbal Behavior, 22, $35-48$.

Sidman, M. (1994). Equivalence relations and behavior: A research story. Boston, MA: Authors Cooperative.

Sidman, M. (2000). Equivalence relations and the reinforcement contingency. Journal of the Experimental Analysis of Behavior, 74, 127-146.

Skinner, B. F. (1957). Verbal behavior. Englewood Cliffs, NJ: Prentice Hall.

Skinner, B. F. (1974). About behaviorism. New York, NY: Alfred A. Knopf.

Stafford, M. W., Sundberg, M. L., \& Braam, S. J. (1988).
A preliminary investigation of the consequences that define the mand and the tact. The Analysis of Verbal Behavior, 6, 61-71.

Sundberg, M. L. (1998). Realizing the potential of Skinner's analysis of verbal behavior. The Analysis of Verbal Behavior, 15, 143-147.

Sundberg, M. L., San Juan, B., Dawdy, M., \& Argüelles, M. (1990). The acquisition of tacts, mands, and intraverbals by individuals with traumatic brain injury. The Analysis of Verbal Behavior, 8, 83-99.

Tenenbaum, H. A. \& Wolking, W. D. (1989). Effects of oral reading rate and inflection on intraverbal responding. The Analysis of Verbal Behavior, 7, 83-89.

Wallace, M. D., Iwata, B. A., \& Hanley, G. P. (2006). Establishment of mands following tact training as a function of reinforcer strength. Journal of Applied Behavior Analysis, 39, 17-24.

Watkins, C. L., Pack-Teixeira, L., \& Howard, J. S. (1989). Teaching intraverbal behavior to severely retarded children. The Analysis of Verbal Behavior, 7, 69-81.

Wheeler, A. J. \& Sulzer, B. (1970). Operant training and generalization of a verbal response form in a speech deficient child. Journal of Applied Behavior Analysis, 3, 139-147.

Yi, J. I., Christian, L., Vittinberga, G., \& Lowenkron, B. (2006). Generalized, negatively reinforced manding in children with autism. The Analysis of Verbal Behavior, 22, 21-33.

Submetido em 27 de agosto de 2007 Aceito em 6 de outubro de 2008 


\title{
INTITUTO BRASILIENSE DE ANÁLISE DO COMPORTAMENTO
}

\author{
www.ibac.com.br
}

Cursos Regulares:

Curso de Especialização em Análise Comportamental Clínica

Carga Horária: 540h - Duração: 2 a 3 anos - conforme opção do aluno

Turmas semestrais - Aulas sábado pela manhã

Clientela: graduados em psicologia

Regulamentado pelo CFP - ABEP

\section{Curso de Especialização em Terapia Analítico Comportamental Infantil \\ Carga Horária: 180h - Duração: 2 anos \\ Turmas a cada 2 anos - Aulas um final de semana por mês \\ Clientela: graduados em psicologia \\ Em processo de regulamentação pelo CFP - ABEP}

\section{Curso de Formação em Análise Comportamental Clínica}

Carga Horária: 500h - Duração: 1 ano e meio

Turmas semestrais - Aulas sábado à tarde

Clientela: graduandos em psicologia a partir do $6^{\circ}$ semestre, psicólogos

\section{Curso de Formação em Terapia Analítico Comportamental Infantil \\ Carga Horária: 180h - Duração: 1 ano e meio \\ Turmas semestrais - Aulas sábado à tarde \\ Clientela: graduandos em psicologia a partir do $7^{\circ}$ semestre, psicólogos}

\section{Curso de Formação em Psicologia Hospitalar e da Saúde \\ Carga Horária: 180h - Duração: 1 ano e meio \\ Turmas semestrais - Aulas sábado pela manhã \\ Clientela: graduandos em psicologia a partir do $6^{\circ}$ semestre, psicólogos}

\section{Cursos de Extensão (30h):}

Análise Comportamental das Relações Amorosas Terapia Sexual

Análise Comportamental do Esporte

Análise Comportamental dos Transtornos Alimentares

\section{Outras Atividades:}

Inglês instrumental para psicólogos

Grupos de Estudo em Análise do Comportamento

Terça-Clínica: Discussão de casos clínicos em AC Cinemateca IBAC

\section{Encontro Regional de Psicologia e Medicina Comportamental 25 e 26 de abril de 2009 Brasília/DF}

